\title{
Evaluation of HOAPS-3 Ocean Surface Freshwater Flux Components
}

\author{
AXEl ANDERSSON* AND CHRISTIAN KLEPP \\ Meteorologisches Institut der Universität, Hamburg, Germany \\ KARSTEN FENNIG ${ }^{+}$ \\ Met Office, Exeter, United Kingdom \\ STEPHAN BAKAN \\ Max-Planck-Institut für Meteorologie, Hamburg, Germany \\ HARTMUT GRASSL \\ Meteorologisches Institut der Universität, Hamburg, Germany \\ JÖRG SCHULZ\# \\ Deutscher Wetterdienst, Satellite Application Facility on Climate Monitoring, Offenbach, Germany
}

(Manuscript received 2 July 2009, in final form 15 August 2010)

\begin{abstract}
Today, latent heat flux and precipitation over the global ocean surface can be determined from microwave satellite data as a basis for estimating the related fields of the ocean surface freshwater flux. The Hamburg Ocean Atmosphere Parameters and Fluxes from Satellite Data (HOAPS) is the only generally available satellite-based dataset with consistently derived global fields of both evaporation and precipitation and hence of freshwater flux for the period 1987-2005. This paper presents a comparison of the evaporation $E$, precipitation $P$, and the resulting freshwater flux $E-P$ in HOAPS with recently available reference datasets from reanalysis and other satellite observation projects as well as in situ ship measurements. In addition, the humidity and wind speed input parameters for the evaporation are examined to identify sources for differences between the datasets. Results show that the general climatological patterns are reproduced by all datasets. Global mean time series often agree within about $10 \%$ of the individual products, while locally larger deviations may be found for all parameters. HOAPS often agrees better with the other satellite-derived datasets than with the in situ or the reanalysis data. The agreement usually improves in regions of good in situ sampling statistics. The biggest deviations of the evaporation parameter result from differences in the nearsurface humidity estimates. The precipitation datasets exhibit large differences in highly variable regimes with the largest absolute differences in the ITCZ and the largest relative biases in the extratropical storm-track regions. The resulting freshwater flux estimates exhibit distinct differences in terms of global averages as well as regional biases. In comparison with long-term mean global river runoff data, the ocean surface freshwater balance is not closed by any of the compared fields. The datasets exhibit a positive bias in $E-P$ of $0.2-$ $0.5 \mathrm{~mm} \mathrm{day}^{-1}$, which is on the order of $10 \%$ of the evaporation and precipitation estimates.
\end{abstract}

* Current affiliation: Max-Planck-Institut für Meteorologie, Hamburg, Germany.

${ }^{+}$Current affiliation: Deutscher Wetterdienst, Satellite Application Facility on Climate Monitoring, Offenbach, Germany.

\# Current affiliation: The European Organisation for the Exploitation of Meteorological Satellites, Darmstadt, Germany.

Corresponding author address: Axel Andersson, Max-Planck-Institut für Meteorologie, Bundesstr. 53, 20146 Hamburg, Germany. E-mail: christian.klepp@zmaw.de

DOI: 10.1175/2010JAMC2341.1 


\section{Introduction}

The successful understanding and modeling of the global climate system requires detailed observation and knowledge of the global water cycle (Trenberth et al. 2007; Allan and Liepert 2010). Especially over the global oceans, measurements of the required quantities are difficult to obtain and ship and buoy measurements suffer from inherent spatial and temporal undersampling.

Microwave and infrared radiometers flown aboard polar orbiting satellites enable us to establish global water cycle datasets from retrievals of relevant ocean and atmospheric parameters such as sea surface temperature, winds, air humidity, and precipitation. Such datasets are provided with a better spatiotemporal sampling in comparison with in situ observations.

The microwave part of the electromagnetic spectrum is ideally suited to retrieve precipitation and parameters useful to estimate latent heat flux and evaporation using a parameterization. At low microwave frequencies the emitted radiation penetrates clouds, resulting in a direct signal of the sea surface state at the satellite receiver with only moderate influence by atmospheric hydrometeors. With the additional use of SST data, estimates of the sea surface evaporation become possible. Moreover, it is possible to detect precipitation by the radiation that is emitted from hydrometeors. At higher microwave frequencies the radiation is strongly influenced by scattering at ice particles, which are an additional indicator for precipitation. The difference of evaporation and precipitation constitutes the ocean freshwater balance that is an important driver of oceanic circulation and atmospheric energy transport.

The Special Sensor Microwave Imager (SSM/I) radiometer aboard the Defense Meteorological Satellite Program (DMSP) satellites, available since 1987, became a foundation for the derivation of surface flux and precipitation time series by various international research groups. Depending on the dataset application purpose, blending and morphing techniques have been developed to combine different satellite and model data with the $\mathrm{SSM} / \mathrm{I}$ time series.

Generally these datasets fall into two categories providing either surface fluxes or precipitation estimates. Prominent surface flux products are the Goddard SatelliteBased Surface Turbulent Fluxes, version 2 (GSSTF2; Chou et al. 2003), the Japanese Ocean Flux Datasets with the Use of Remote Sensing Observations (J-OFURO 2; Kubota and Tomita 2007), the objectively analyzed airsea fluxes (OAFlux; Yu and Weller 2007; Yu et al. 2008), and the merged flux dataset of the Institut Français de Recherche pour l'Exploration de la Mer (IFREMER; Bentamy et al. 2003). Well-known and widely used precipitation products for a variety of applications are the Global Precipitation Climatology Project (GPCP; Huffman et al. 1997; Adler et al. 2003), the Tropical Rainfall Measuring Mission (TRMM) Multisatellite Precipitation Analysis (TMPA; Huffman et al. 2007), the Climate Prediction Center (CPC) Merged Analysis of Precipitation (CMAP; Xie and Arkin 1997), the Unified Microwave Ocean Retrieval Algorithm (UMORA; Hilburn and Wentz 2008), the Global Satellite Mapping of Precipitation (GSMaP; Kubota et al. 2007), and Precipitation Estimation from Remotely Sensed Information using Artificial Neural Networks (PERSIANN; Hsu et al. 1997).

The combination of such satellite-retrieved datasets results in estimates of the global ocean freshwater flux. Schlosser and Houser (2007) state that this is a highly required but difficult task, as differently calibrated time series and inhomogeneous data sources have to be combined while there is no comprehensive in situ validation data available.

Alternatively, reanalysis datasets, such as the 40-yr European Centre for Medium-Range Weather Forecasts (ECMWF) Re-Analysis (ERA-40; Uppala et al. 2005) and ERA-Interim (ERA-Int; Simmons et al. 2007), National Centers for Environmental Prediction (NCEP) NCEP-1 (Kalnay et al. 1996), NCEP-2 (Kanamitsu et al. 2002), or the Japanese 25-year Reanalysis (JRA-25) (Onogi et al. 2007), provide the relevant water cycle parameters. For the ocean surface fluxes, ship observations give the opportunity to derive global ocean datasets, such as the National Oceanography Centre Southampton (NOCS) surface flux dataset (Berry and Kent 2009).

In contrast, the Hamburg Ocean Atmosphere Parameters and Fluxes from Satellite Data (HOAPS) has been developed with the goal to derive the parameters required to retrieve the global ocean surface freshwater flux components consistently within one entirely satellitebased dataset (Andersson et al. 2010b). For the sake of long-term homogeneity the approach for HOAPS is to use the SSM/I as the common data source for all retrievals instead of combining different data sources. This ensures a uniform sampling for all parameters and avoids complications with the cross calibration and the implementation of retrieval procedures for different types of sensors. Another criterion for the design of the dataset is to use stand-alone retrieval procedures that only rely on SSM/I brightness temperatures and the Advanced Very High Resolution Radiometer (AVHHR)-based SST as input and are independent of ancillary input data, such as additional first guess fields from model output.

Previous studies (e.g., Brunke et al. 2002; Chou et al. $2003,2004)$ indicate large deviations in the comparison of different flux datasets. From a comparison with buoy 
data Bourras (2006) assumed the overall regional accuracy of satellite-derived fluxes to be on the order of $20 \%-30 \%$. To use satellite-derived fluxes for quantitative analyses, Bourras (2006) suggests that these errors need to be $5 \%-10 \%$ lower.

Similar numbers were found in comparisons for satellite-derived precipitation datasets (e.g., Adler et al. 2001; Beranger et al. 2006). In particular, the tropical regions and the high latitudes are prone to large differences between precipitation estimates. Moreover, reanalysisbased estimates of evaporation and in particular precipitation tend to perform poor over the oceans because of the limited availability of assimilated in situ data over the oceans. The lack of long-term ground truth data with good spatial coverage is also the reason why validation studies over the ocean are difficult. The coverage of ship data often strongly depends on the general shipping routes, leading to larger errors in regions with sparse sampling.

To date, intercomparison studies are the most appropriate way of global-scale evaluation for evaporation and precipitation products to asses their systematic differences as a measure of methodological uncertainties. The assessment of spatial pattern consistency and systematic differences on climatological scale between HOAPS-3 and other evaporation and precipitation estimates and the resulting freshwater flux is the main aim of the evaluation presented in this paper.

Several recent readily available products are selected for comparison. These products are derived from different data sources and represent model-based estimates from a reanalysis dataset, in situ measurements from ships, and different satellite-based datasets that include sensors not utilized in HOAPS. For the evaporation these are the ERA-Int reanalysis, the ship-measurementbased NOCS V2 dataset, and the satellite-databased IFREMER V3 flux dataset. The HOAPS precipitation product is compared with ERA-Int and the two satellite-based products, GPCP V2 and TRMM 3B43.

Additionally, the input parameters for the evaporation retrieval, wind, and sea-air humidity difference are assessed. All used time series have a temporal overlap with HOAPS-3 of more than one decade from January 1992 to December 2005. The resulting comparison period of 14 years is an advance over previous studies that are mostly limited to substantially shorter time periods. However, some of these estimates are not fully independent as input data from the same observations may be used. Scatterometer wind speeds or ship observations are, for example, assimilated into the ERA-Int reanalysis and SSM/I brightness temperatures are used in ERA-Int and also in the satellite-based products.

An introduction to HOAPS-3 along with an overview of the other datasets used in this study is given in section 2 .
The climatological comparisons between HOAPS-3 and the other products are shown in section 3 . The results and implications for the individual parameters and products are discussed in section 4. A conclusion and an outlook are given in section 5 .

\section{Data}

\section{a. HOAPS-3}

A comprehensive documentation of the HOAPS-3 retrieval procedures and is given in Andersson et al. (2010b). The relevant details are summarized in the following.

Because of the specific goal of HOAPS to derive the global ocean freshwater flux consistently from SSM/I radiometers, a full processing chain for the SSM/I raw data has been implemented. As an important part of the processing an intersensor calibration is applied to avoid spurious biases in the time series between the successive sensors. The intersensor calibration is based on a statistical approach to homogenize the SSM/I brightness temperatures and uses the radiometer on the DMSP $F-11$ as a calibration reference (Andersson et al. 2010b).

As sea ice-covered regions and landmasses have to be excluded from the retrievals, an ice mask is calculated based on the National Aeronautics and Space Administration (NASA) "Team" sea ice algorithm (Swift et al. 1985) and a high-resolution land-sea mask is applied.

\section{1) EVAPORATION}

The HOAPS-3 evaporation is calculated with the Coupled Ocean-Atmosphere Response Experiment (COARE) 2.6a bulk flux algorithm (Fairall et al. 1996, 2003), requiring retrievals of wind speed $(u)$, sea surface saturation specific humidity $\left(q_{s}\right)$, and surface atmospheric specific humidity $\left(q_{a}\right)$ as input:

$$
Q_{l}=\rho L_{E} C_{E} u\left(q_{s}-q_{a}\right) .
$$

The evaporation $(E)$ follows with

$$
E=Q_{l} /\left(L_{E} \rho_{0}\right),
$$

where $\rho$ is moist air density (calculated using $q_{a}$, the estimated air temperature, and a pressure of $1013.25 \mathrm{hPa}$ ), $L_{E}$ is the latent heat of evaporation (calculated SST dependent), $C_{E}$ is the Dalton number, and $\rho_{0}$ is the freshwater density as a function of temperature.

The near-surface wind speed is directly related to the SSM/I brightness temperatures because the ocean-surface emissivity changes with wind speed. In HOAPS-3, a neural network-based algorithm is used that permits the strong nonlinearity of the problem (cf. Andersson et al. 2010b) to be addressed. 
$\mathrm{SSM} / \mathrm{I}$ measurements are sensitive to the atmospheric water vapor content in the lower boundary layer (Schulz et al. 1993). For HOAPS-3, the linear relationship of Bentamy et al. (2003) is used to retrieve the near-surface atmospheric specific humidity $\left(q_{a}\right)$.

In case of strong precipitation the retrieval of the wind speed and $q_{a}$ and therefore of turbulent fluxes is not possible from SSM/I observations. The impact of these missing data on the evaporation mean fields is discussed in section $4 \mathrm{~d}$.

Since the SSM/I is not suited for accurate SST retrievals, additional SST information is needed for the retrieval of turbulent heat flux parameters. To rely exclusively on satellite data, the SST is taken from the National Oceanographic Data Center/Rosenstiel School of Marine and Atmospheric Science (NODC/RSMAS) Pathfinder, Version 5.0, dataset (Casey 2004; NODC 2008), which is based on AVHHR measurements. The sea surface saturation specific humidity $\left(q_{s}\right)$ is calculated from the AVHRR SST measurements using the Magnus formula (Murray 1967) and a constant salinity correction factor of 0.98 .

The parameterization of the bulk transfer coefficient $C_{E}$ additionally depends on the air temperature, which is estimated from the sea surface temperature by the mean of the assumptions of $80 \%$ humidity and $1 \mathrm{~K}$ sea-air temperature difference. However, the impact of these assumptions on the accuracy of $C_{E}$ is regarded to be of secondary order (Liu et al. 1994).

\section{2) PREcipitation}

Similar to the wind speed retrieval, the HOAPS precipitation algorithm is based on a neural network approach. The neural network was trained with a dataset of assimilated SSM/I brightness temperatures and the corresponding precipitation values of the ECMWF model covering a variety of precipitation events. The resulting stand-alone retrieval algorithm does not use any ancillary information and relies exclusively on SSM/I brightness temperatures.

\section{3) FreshwATER FLUX}

The freshwater flux is computed as the difference between the spatial and temporal averages of evaporation and precipitation at each grid box. This balance is not available at each individual SSM/I observation pixel, as in cases of strong precipitation neither wind speed nor $q_{a}$ can be derived reliably.

\section{4) DATA PRODUCTS}

HOAPS-3 monthly mean, pentad mean, and twice daily gridded data products cover the time period between July 1987 and the end of December 2005 and can be freely obtained from the Web site www.hoaps.org. In this study the HOAPS-3 monthly mean gridded product (HOAPS-G) with a resolution of 0.5 is used (Andersson et al. 2007) for the evaluation period 1992 to 2005 .

\section{b. Datasets for comparison with HOAPS}

\section{1) IFREMER SATELLITE-DERIVED TURBULENT FLUXES V3}

Bentamy et al. (2003) developed at IFREMER a remotely sensed dataset of wind stress and surface turbulent latent and sensible heat fluxes. Here the version 3.0 is used, which is currently available for the time period from March 1992 to December 2007 (Bentamy et al. 2008). It utilizes different input sources to derive the flux parameters using the COARE 3.0 algorithm (Fairall et al. 2003). As in HOAPS-3, $q_{a}$ is estimated from SSM/I data with the algorithm described in Bentamy et al. (2003). In contrast to HOAPS-3, the IFREMER wind speed is derived from a combination of retrievals based on scatterometers and SSM/I data. The flux fields are retrieved using a kriging method to merge the various satellite estimates. The SST is taken from the National Oceanic and Atmospheric Administration (NOAA)Optimum Interpolation (OI) weekly product.

\section{2) NOCS v2.0}

The NOCS v2.0 surface flux dataset by Berry and Kent (2009) is exclusively based on Voluntary Observing Ship (VOS) data from the International Comprehensive Ocean-Atmosphere Data Set (ICOADS; Worley et al. 2005). The NOCS dataset provides fields of marine surface meteorology and fluxes over the global ocean that are constructed using a bias adjustment procedure and an optimum interpolation method. The turbulent fluxes are derived with the bulk parameterization of Smith (1980, 1988).

\section{3) GPCP V2}

The GPCP, version 2, combined product (Adler et al. 2003) provides fields of satellite-derived precipitation retrieved from passive microwave and infrared data. For the merging procedure the infrared precipitation estimates from geosynchronous satellites are constantly calibrated with the passive microwave precipitation retrievals from polar orbiting satellites, which are considered to be of higher accuracy. Different from HOAPS, GPCP provides also precipitation observations over land, where the analysis also makes use of surface data from rain gauges.

\section{4) TRMM 3B43}

In the 3B43 product, data from the TRMM Microwave Imager (TMI) and the precipitation radar (PR) 

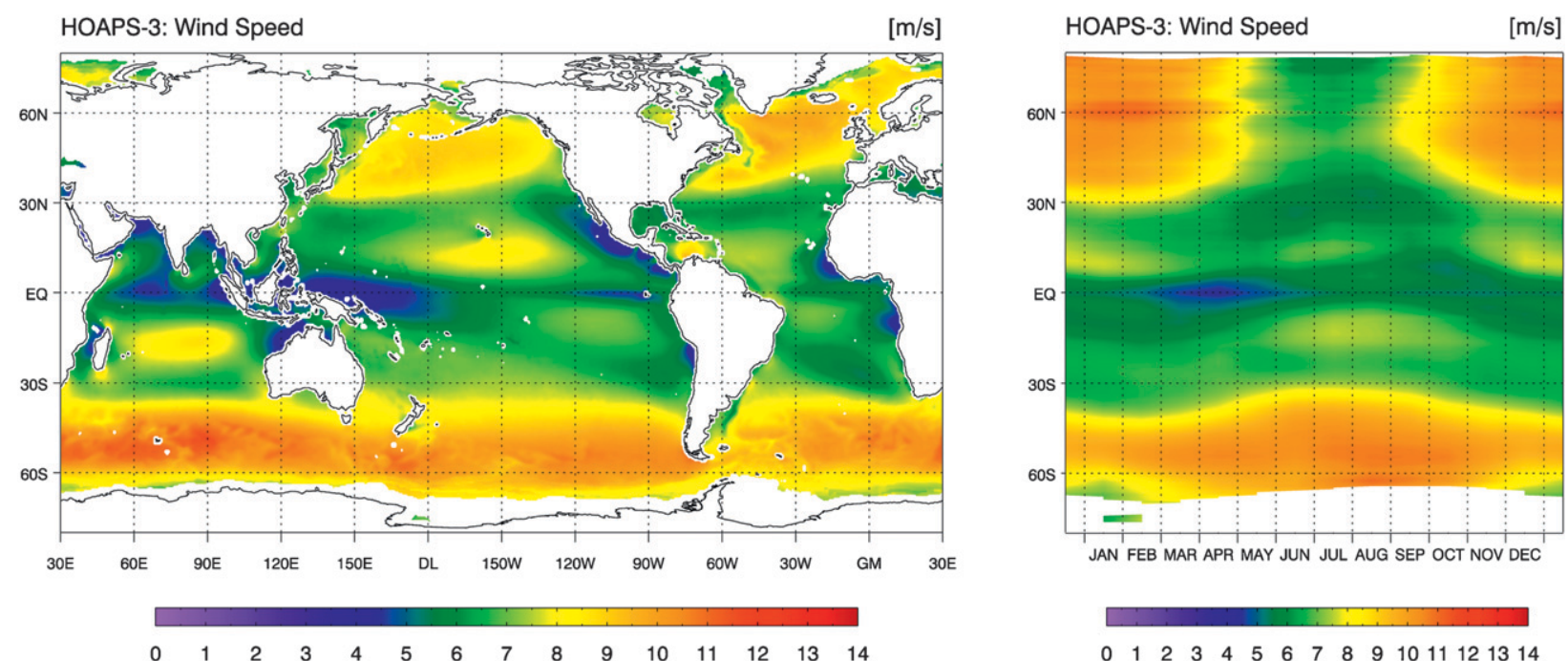

FIG. 1. (left) Climatological mean field and (right) zonal mean annual cycle of HOAPS-3 wind speed for the years 1988-2005.

are blended with SSM/I and geosynchronous precipitation data. In analogy to the GPCP product, microwave and infrared retrievals are used to complement the TRMM precipitation retrievals. The TRMM Combined Instrument (TCI) precipitation data from PR and TMI are used as the calibration reference for the microwave and infrared retrievals to derive a "best-estimate precipitation rate." The $3 \mathrm{~B} 43$ product is available for the period after 1998 and is limited to the region between $50^{\circ} \mathrm{S}$ and $50^{\circ} \mathrm{N}$.

\section{5) ERA-INTERIM}

ERA-Interim is the latest and improved global atmospheric reanalysis dataset provided by the ECMWF (Simmons et al. 2007). It uses an advanced data assimilation scheme and additional observations from various sources in comparison with ERA-40. At present the ERA-Int record starts at 1989. Fields of wind speed, $q_{a}$, evaporation, and precipitation were obtained from the 12 -h forecast. As a $q_{a}$ parameter for the near-surface layer is not directly available in the ERA-Int archive, it was calculated from the 12-h forecast values of 2-m air temperature, 2-m dewpoint temperature, and surface pressure.

\section{c. Methodology}

For the following comparisons a common time period from 1992-2005 is chosen, which is covered by all datasets except for the TRMM product, which starts only in 1998. Since TRMM products are the only long-term satellite-based precipitation dataset that includes precipitation radar data, it is included in the comparisons.

The HOAPS land-sea and ice masks were applied to all datasets to achieve a common spatial coverage of the global ice-free oceans similar to the HOAPS-G datasets.
Apart from the differences of the mean fields for the 1992-2005 period, the respective zonal means have been calculated as well as the time series of the monthly global mean values.

For ERA-Int the ocean surface freshwater flux fields were calculated by subtracting the respective evaporation and precipitation monthly mean grid values. Additionally, the IFREMER evaporation and GPCP precipitation were subtracted from each other to provide a second freshwater flux product for comparison.

\section{Climatological evaluation of HOAPS freshwater flux parameters}

\section{a. Wind speed}

\section{1) Global Distribution AND ANNUAL CYCLE}

HOAPS climatological mean wind speed for the years 1988-2005 is shown in the left panel of Fig. 1. North Atlantic and Pacific storm-track regions as well as the "roaring forties" and "furious fifties" over the Southern Ocean are characterized by maximum climate mean values of up to $14 \mathrm{~m} \mathrm{~s}^{-1}$. Secondary local maxima exist in the tropical trade wind area. Moreover, the characteristic minima of the subtropical calms and the Southeast Asian warm pool region are clearly evident. The zonal mean annual cycle (Fig. 1, right) highlights the wintertime maxima of wind speed in the mid- and high latitudes of both hemispheres, while only weak variability occurs in the subtropical regions.

\section{2) COMPARISON OF CLIMATOLOGICAL MEANS}

The comparison of HOAPS wind speed with ERAInt, NOCS, and IFREMER is depicted in Fig. 2. The top 

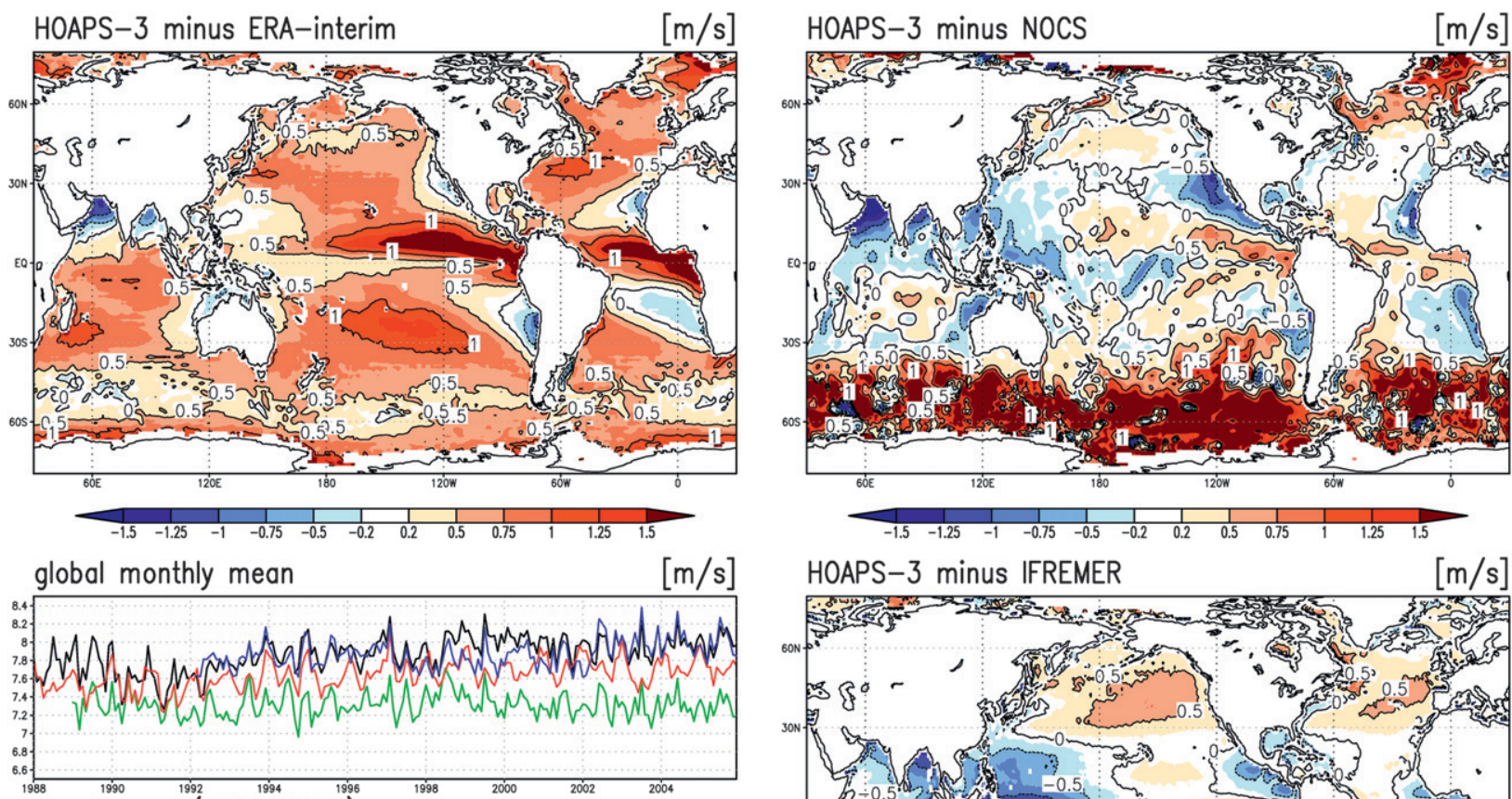

zonal mean $(1992-2005)$

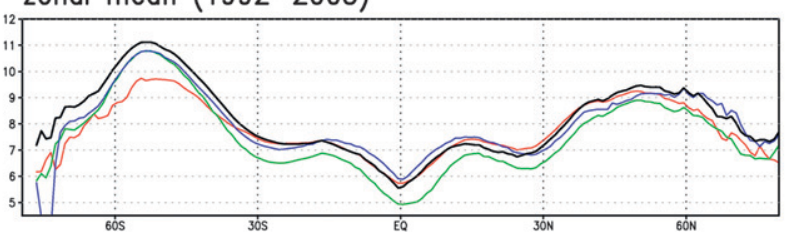

- HOAPS-3 - ERA-int - NOCS — IFREMER

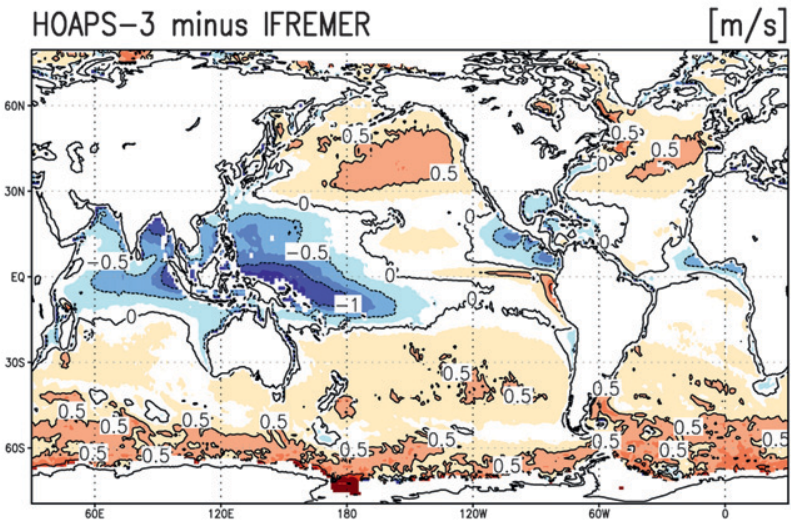

FIG. 2. Difference of the 1992-2005 climate mean HOAPS-3 wind speed and (upper left) ERA-Int,(upper right) NOCS v2.0, and (lower right) IFREMER flux. (lower left) The global monthly mean wind speed time series of each dataset (upper panel) the zonal mean wind speed for the overlapping time period 1992-2005 (lower panel).

left panel shows the wind speed difference between HOAPS and ERA-Int. Red colors indicate regions where HOAPS exhibits on average higher values, while in blue-shaded regions HOAPS is lower than the compared dataset.

ERA-Int wind speeds are generally lower relative to all other products over the global oceans. A mean bias of $0.60 \mathrm{~m} \mathrm{~s}^{-1}$ relative to HOAPS is found for the global ocean. A similar behavior in the comparison of satelliteretrieved wind speed with reanalysis data was found in earlier studies (Meissner et al. 2001; Kelly et al. 2001; Monahan 2006).

Apart from the general bias, other distinct local differences in the comparison of HOAPS and ERA-Int (Fig. 2, top left) occur in the intertropical convergence zone (ITCZ), where ERA-Int is significantly lower relative to the other datasets.

In regions with cold surface currents, such as the Antarctic Circumpolar Current (ACC) or the upwelling regions on the western continental boundaries, HOAPS and ERA-Int show comparable values within $0.5 \mathrm{~m} \mathrm{~s}^{-1}$ (5\%). The largest negative bias is found over the Arabian Sea and over the Bay of Bengal. Similar patterns are evident in the difference plot of HOAPS and NOCS (Fig. 2, top right). HOAPS wind speeds are about $1 \mathrm{~m} \mathrm{~s}^{-1}$ $(10 \%)$ lower relative to NOCS at the western boundaries of the continents.

Most notably, the IFREMER product exhibits a significant bias in the region of the precipitation maximum of the western tropical Pacific and the warm pool. The IFREMER wind speeds exceed HOAPS by up to $1.5 \mathrm{~m} \mathrm{~s}^{-1}(>20 \%)$ in this region.

Apart from the distinct differences over the warm pool and over the upwelling regions, the deviations between HOAPS, NOCS, and IFREMER are mostly below $0.5 \mathrm{~m} \mathrm{~s}^{-1}(<5 \%)$ in the tropics and midlatitudes with the tendency of HOAPS to show slightly higher mean wind speeds.

At high latitudes the NOCS dataset exhibits a systematic low bias relative to HOAPS and the other 

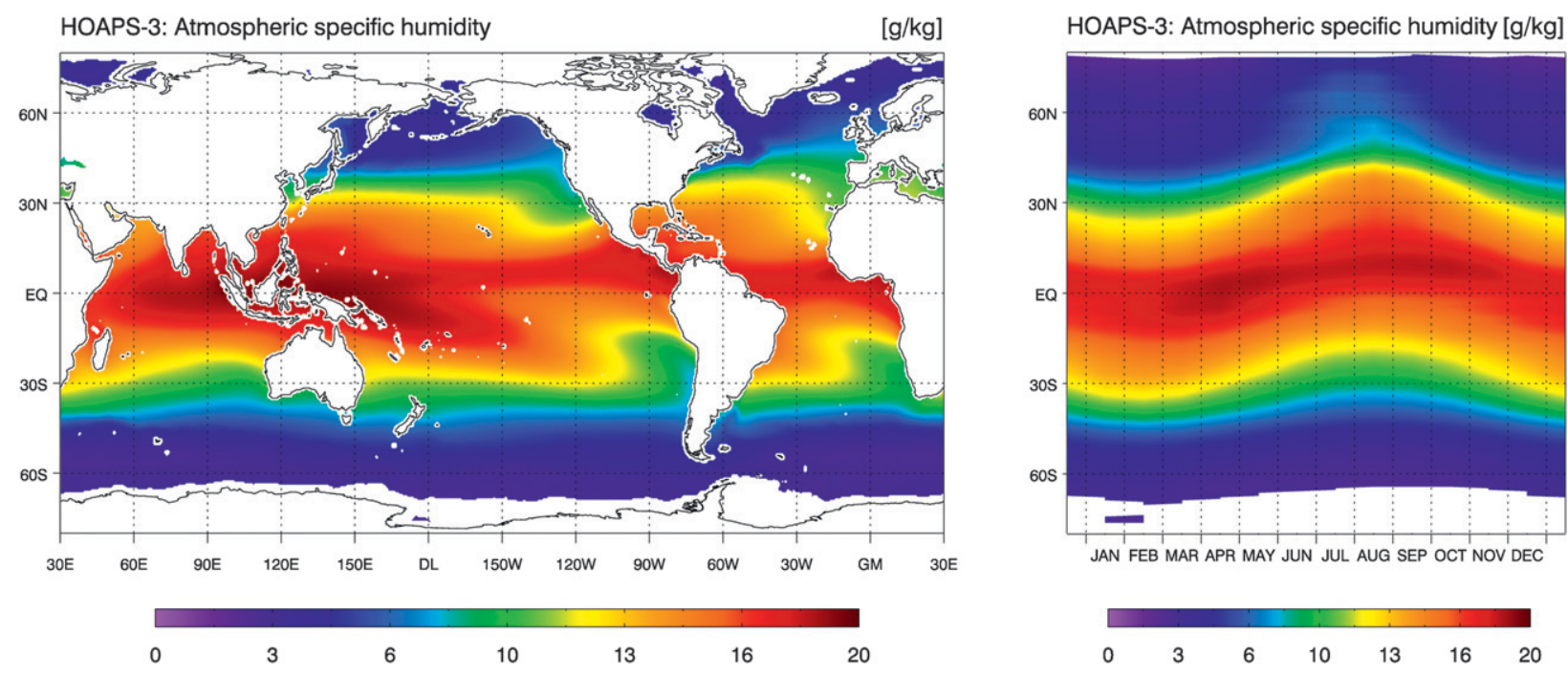

FIG. 3. As in Fig. 1, but for near-surface atmospheric specific humidity $\left(q_{a}\right)$.

datasets. In particular over the Southern Ocean the NOCS wind speed appears to be systematically underestimated. This is also reflected in the total error estimate given in the NOCS dataset, which is around $3.5-4 \mathrm{~m} \mathrm{~s}^{-1}$ for the region south of $40^{\circ} \mathrm{S}$, because of the sparse data sampling.

\section{3) GLOBAL MEAN TIME SERIES AND ZONAL MEANS}

The monthly global mean time series of HOAPS and IFREMER (Fig. 2, lower left) agree in magnitude and variability while the NOCS time series exhibits a constantly low bias of about $0.2 \mathrm{~m} \mathrm{~s}^{-1}$. The latter is mostly due to the low bias of NOCS at high latitudes as shown in the zonal means. Apart from the constant low bias, the structure of the zonal mean for ERA-Int compares well to the other datasets. The locations of the latitudinal maxima and minima are similar for all products.

\section{b. Near-surface atmospheric specific humidity}

\section{1) Global Distribution And AnNuAl CyCle}

HOAPS climatological mean near-surface atmospheric specific humidity $\left(q_{a}\right)$ and its yearly cycle is shown in Fig. 3. The highest values of up to $20 \mathrm{~g} \mathrm{~kg}^{-1}$ of the climate mean $q_{a}$ are found in the tropical warm pool region and the ITCZ. Toward the subpolar regions the values steeply decrease below $2 \mathrm{~g} \mathrm{~kg}^{-1}$. The annual cycle (Fig. 3, right panel) clearly shows the movement of the tropical $q_{a}$ maximum with the position of the sun.

\section{2) COMPARISON OF ClimATOLOgicAl MEANS}

The comparison of $q_{a}$ between HOAPS and ERA-Int (Fig. 4, top left) exhibits the most distinct differences in the tropical and subtropical regions. Positive biases in the warm pool region exceed $1 \mathrm{~g} \mathrm{~kg}^{-1}(<10 \%)$ and reach $2 \mathrm{~g} \mathrm{~kg}^{-1}(20 \%)$ over the eastern Atlantic and eastern Pacific. In the subtropical central Pacific between $10^{\circ}$ and $20^{\circ} \mathrm{HOAPS} q_{a}$ is systematically lower relative to ERA-Int on both hemispheres.

The comparison with NOCS (Fig. 4, top right) reveals a similar pattern that is shifted toward a more negative bias. In particular in the subtropical regions HOAPS is partly more than $2 \mathrm{~g} \mathrm{~kg}^{-1}(20 \%)$ lower relative to NOCS. Between $40^{\circ} \mathrm{S}$ and $60^{\circ} \mathrm{S}$ NOCS is systematically higher relative to all other datasets by up to $1.5 \mathrm{~g} \mathrm{~kg}^{-1}$ (30\%, locally up to $50 \%$ ).

The HOAPS and IFREMER datasets use the same algorithm to derive $q_{a}$ from SSM/I measurements (Bentamy et al. 2003). As may be expected, the comparison reveals only minor differences between both products. The deviations between HOAPS and IFREMER (Fig. 4, lower right) are overall small with $\pm 0.5 \mathrm{~g} \mathrm{~kg}^{-1}$ in parts of the tropical regions and over the Kuroshio and Gulf Stream. This is within $5 \%$ for the most regions, locally within $10 \%$. In the tropical belt the general tendency of the regional differences is similar to the previous comparisons, with IFREMER being much closer to HOAPS than to the other products.

\section{3) GLOBAL MEAN TIME SERIES AND ZONAL MEANS}

The global mean time series of all datasets (Fig. 4, lower left) agree in magnitude and variability with the NOCS dataset being slightly higher relative to the other datasets. Also the zonal mean values of all datasets (Fig. 4, lower left) show very similar characteristics. The NOCS dataset is generally moister between $20^{\circ}$ north and 

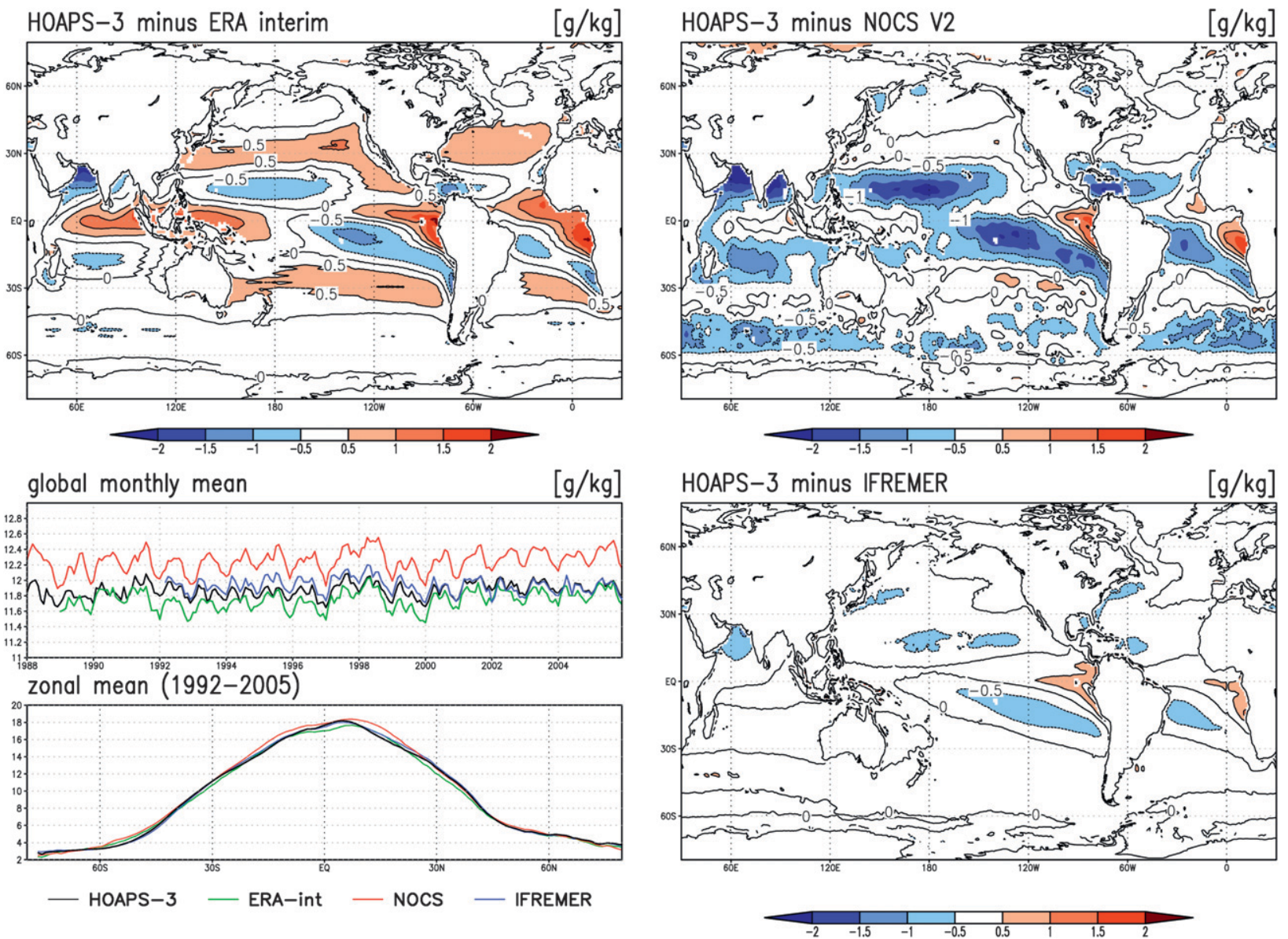

FIG. 4. As in Fig. 2, but for near-surface atmospheric specific humidity $\left(q_{a}\right)$.

south relative to the satellite retrieval of Bentamy et al. (2003), which is used in HOAPS and IFREMER. Hence, the NOCS monthly global mean $q_{a}$ values are on average $0.35 \mathrm{~g} \mathrm{~kg}^{-1}$ higher relative to HOAPS. ERA-Int exhibits the lowest zonal mean values in the equatorial region as well as around $30^{\circ}$ north and south, which results in global mean values that are on average $0.13 \mathrm{~g} \mathrm{~kg}^{-1}$ lower relative to HOAPS.

\section{c. Evaporation}

\section{1) Global Distribution AND ANNUAL CYCLE}

The mean global ocean evaporation (Fig. 5, left panel) shows the well-known climatological distributions with strong maxima over both hemispheres with values of up to $7 \mathrm{~mm} \mathrm{day}{ }^{-1}$. Mid- and high latitudes exhibit generally lower values of less than $3 \mathrm{~mm}$ day $^{-1}$ with the exception of the warm boundary currents of the Kuroshio, the Gulf Stream, and the Agulhas Current. The Gulf Stream generates the highest mean evaporation values on the globe of up to $8 \mathrm{~mm}$ day $^{-1}$. A pronounced seasonal variability can be identified in the climatological zonal mean annual cycle (Fig. 5, right panel) with maximum evaporation values in the trade wind belts and secondary maxima in the mid- and high-latitude storm-track regions during the winter season of each hemisphere.

\section{2) COMParison of Climatological MEANS}

The difference patterns for all datasets in Fig. 6, especially over the subtropics, are similar to the climatological mean field pattern of HOAPS evaporation (Fig. 5). They show higher difference values in regions of large evaporation and smaller values in regions with low evaporation. Furthermore, the differences appear to be determined to a large extent by the humidity fields. This is most distinct in the comparison of HOAPS with NOCS and ERA, while the comparison with the IFREMER dataset exhibits some similar tendencies, but mostly smaller values below $1 \mathrm{~mm} \mathrm{day}^{-1}$. The magnitudes of the deviations are regionally largest in the comparison with NOCS, reaching more than $1.5 \mathrm{~mm}$ day $^{-1}$ or $20 \%$ of the average value. In the comparison 

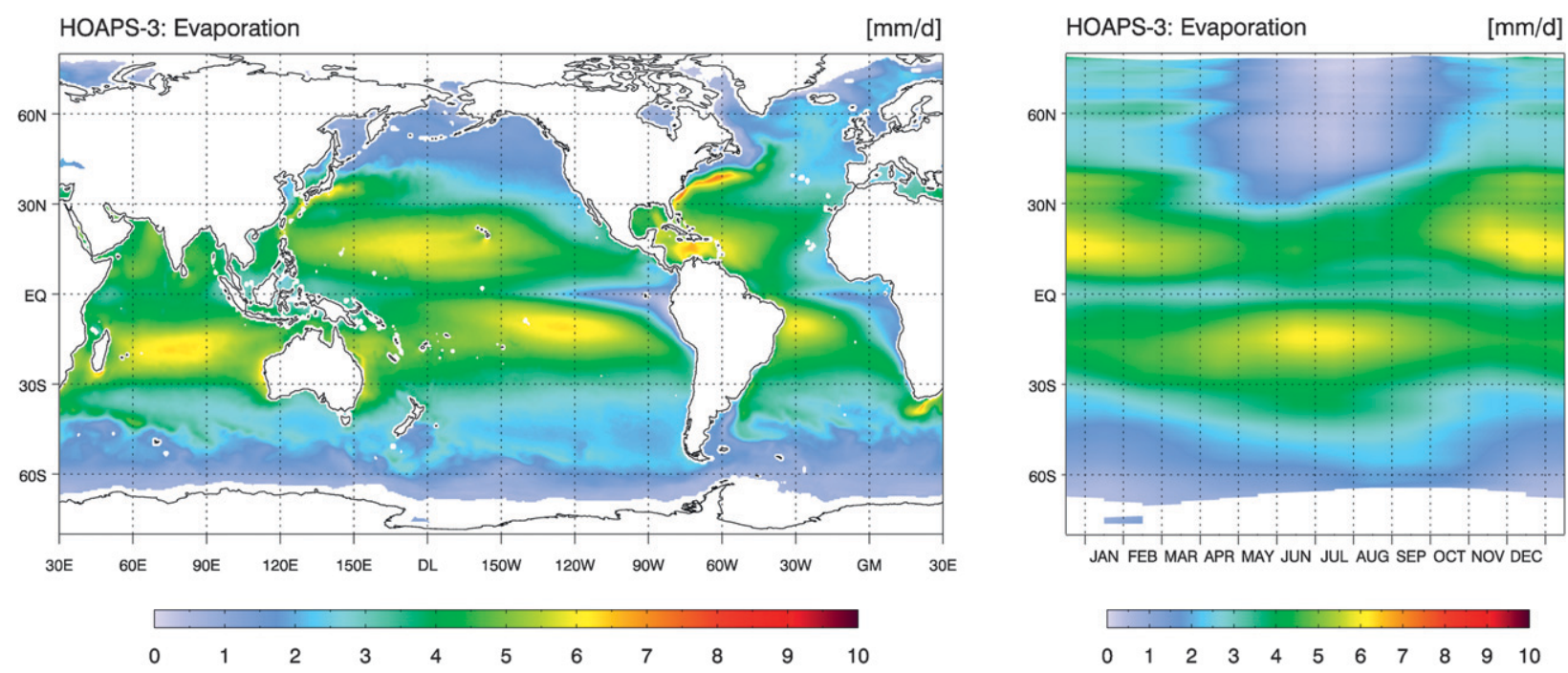

FIG. 5. As in Fig. 1, but for evaporation.

with IFREMER the relative differences are generally below $5 \%-10 \%$.

In a broad band from the Kuroshio over the North Pacific to the North American east coast ERA-Int and NOCS evaporation is systematically higher relative to HOAPS. This pattern continues southward along the Baja California. Over the cold tongue in the eastern equatorial Pacific and the Southeast Asian warm pool HOAPS evaporation is systematically lower relative to all other datasets. Because of the fairly small absolute values of evaporation, the relative error reaches more than $30 \%$ in these regions.

A low bias of HOAPS is evident in the eastern tropical Atlantic with differences of more than $1 \mathrm{~mm}^{-1 a y}{ }^{-1}$ (up to $50 \%$ ) because of a combination of an overestimation of $q_{a}$ along the West African coast and an underestimation of $q_{s}$ in the tropical and subtropical Atlantic. The latter effect can be identified in the difference of HOAPS and IFREMER evaporation fields, which is not influenced by strong $q_{a}$ biases between these datasets.

Over the North Atlantic and North Pacific between $40^{\circ}$ and $80^{\circ} \mathrm{N}$ the comparison between the datasets shows mixed results with differences that are mostly below $0.5 \mathrm{~mm} \mathrm{day}{ }^{-1}$. While the agreement of HOAPS is best with ERA-Int, NOCS exhibits mostly lower values, and IFREMER tends to be slightly higher than HOAPS.

Over the storm tracks of the southern mid-high latitudes, NOCS and HOAPS exhibit the largest differences coinciding with the Southern Hemisphere's band of strong winds between $40^{\circ}$ and $60^{\circ} \mathrm{S}$ (see Fig. 2). The mean evaporation of NOCS is locally more than $1.5 \mathrm{~mm} \mathrm{day}^{-1}$ below HOAPS values, which corresponds to a relative difference of more than $50 \%$ in these regions. The corresponding error estimate given in the NOCS product exceeds $100 \%$.

Relative to ERA-Int, the HOAPS evaporation is up to $0.75 \mathrm{~mm} \mathrm{day}^{-1}$ (more than $30 \%$ ) higher for the southern midlatitude storm tracks. This is mainly related to differences in $q_{s}-q_{a}$ (not shown), since HOAPS and ERA-Int wind speed (Fig. 2, lower right) agree well for the midlatitudes of the Southern Hemisphere.

\section{3) GLOBAL MEAN TIME SERIES AND ZONAL MEANS}

The comparison of the climatological zonal means (Fig. 6 , lower left) shows an overall agreement in the location and magnitude of the maxima and minima of all datasets. In the southern midlatitudes HOAPS and IFREMER agree best, while ERA-Int and NOCS exhibit significantly lower values. The largest deviations of up to $50 \%$ occur for the NOCS dataset in the data-sparse southern oceans and subtropics. In the tropical regions, the maxima in the NOCS dataset are less pronounced in comparison with the other datasets, while HOAPS exhibits the lowest values of all datasets around the equator. This is mainly due to the low bias over the tropical Atlantic and the cold tongue in the eastern tropical Pacific.

The magnitude of the global monthly mean time series is in close agreement for all datasets. In particular from 1995 onward, the biases are remarkably small. HOAPS and NOCS values are very close for the entire time series, except for the period after the eruption of Mount Pinatubo, when the HOAPS is impaired by a cold bias in the SST dataset (Andersson et al. 2010b). The major effect on the flux retrievals is evident before the start of the comparison time period in 1992. The 

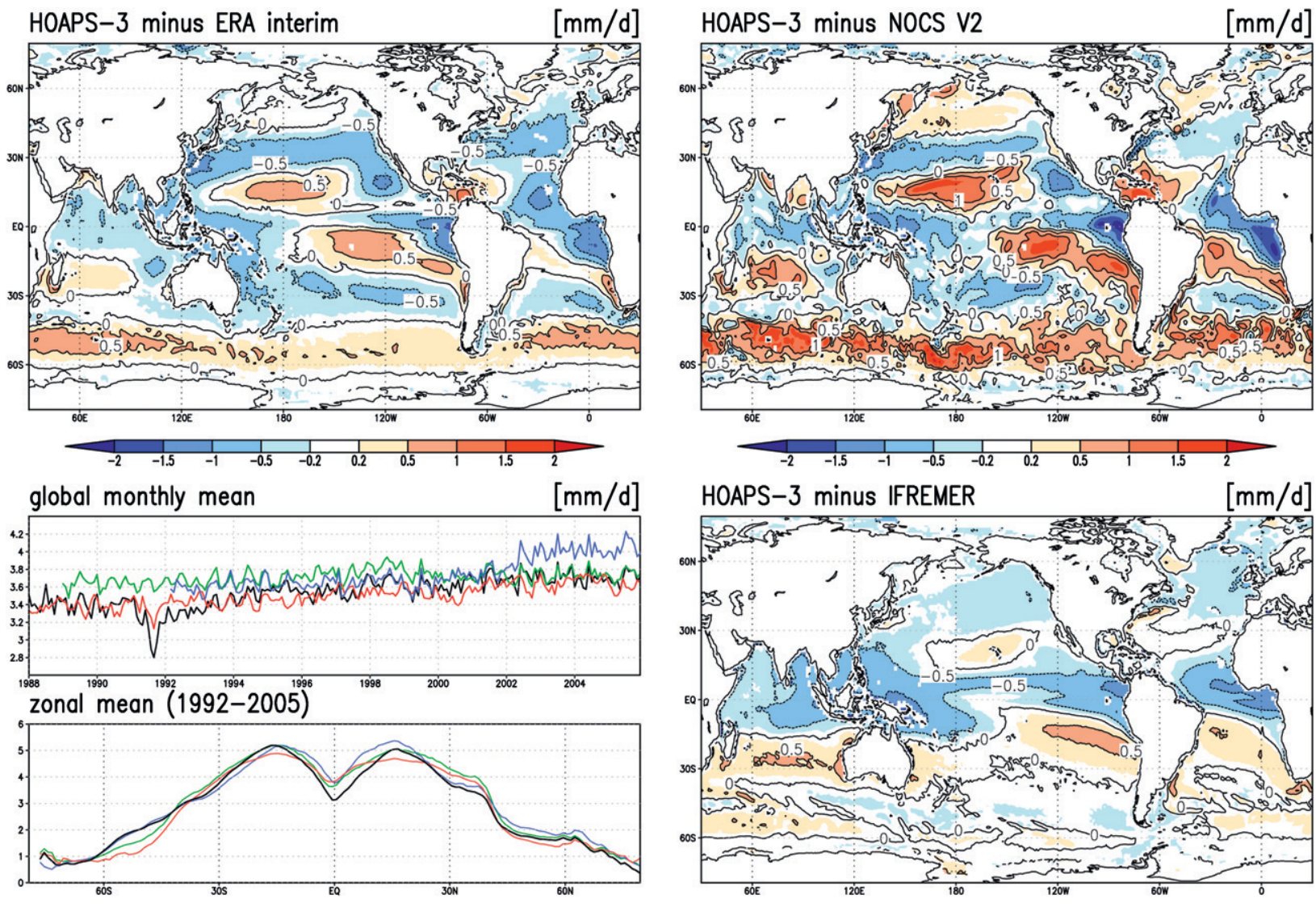

- HOAPS-3 - ERA-int NOCS - IFREMER

FIG. 6. As in Fig. 2, but for evaporation.

sudden increase of the IFREMER time series in 2002 is likely to be an artifact from the wind or SST input data sources. However, this does not affect the general difference patterns.

The variability of the global monthly mean time series of HOAPS and IFREMER is very similar with a standard deviation of $0.18 \mathrm{~mm} \mathrm{day}^{-1}$. The corresponding values for NOCS and ERA-Int are 0.13 and $0.09 \mathrm{~mm} \mathrm{day}^{-1}$, respectively. However, for the time period between 1995 and 2001 the standard deviations of all datasets range from 0.08 to $0.10 \mathrm{~mm} \mathrm{day}^{-1}$.

\section{d. Precipitation}

\section{1) Global distribution AND ANNUAl CYCle}

The climatological mean precipitation from HOAPS (Fig. 7, left panel) well represents the known global distribution of precipitation. Dominant features are the overall highest rain rates in the ITCZ, exceeding $10 \mathrm{~mm}^{\text {day }}{ }^{-1}$, and the regional maxima over the tropical Indian Ocean and the South Pacific conversion zone (SPCZ). The North
Atlantic and Pacific storm tracks are also clearly identifiable with maximum values of up to $9 \mathrm{~mm} \mathrm{day}^{-1}$ over the Gulf Stream and Kuroshio. Global precipitation minima can be observed in the so-called subtropical oceanic deserts in the eastern subtropical Atlantic and Pacific.

The zonal mean annual cycle (Fig. 7, right panel) clearly shows the seasonal displacement of the ITCZ as well as the high precipitation values over the Northern Hemisphere storm tracks during the cold season. Also the development of the Southern Hemisphere subtropical maximum in the SPCZ between January and April is evident.

\section{2) COMPARISON OF CLIMATOlOgiCAL MEANS}

ERA-Int precipitation is generally higher on global scale than all satellite-derived products as depicted in the difference plot of HOAPS and ERA-Int and the global monthly mean time series of the datasets in Fig. 8. This bias originates mainly from the tropical belt, where ERAInt exceeds HOAPS partly by more than $2 \mathrm{~mm} \mathrm{day}^{-1}$ 

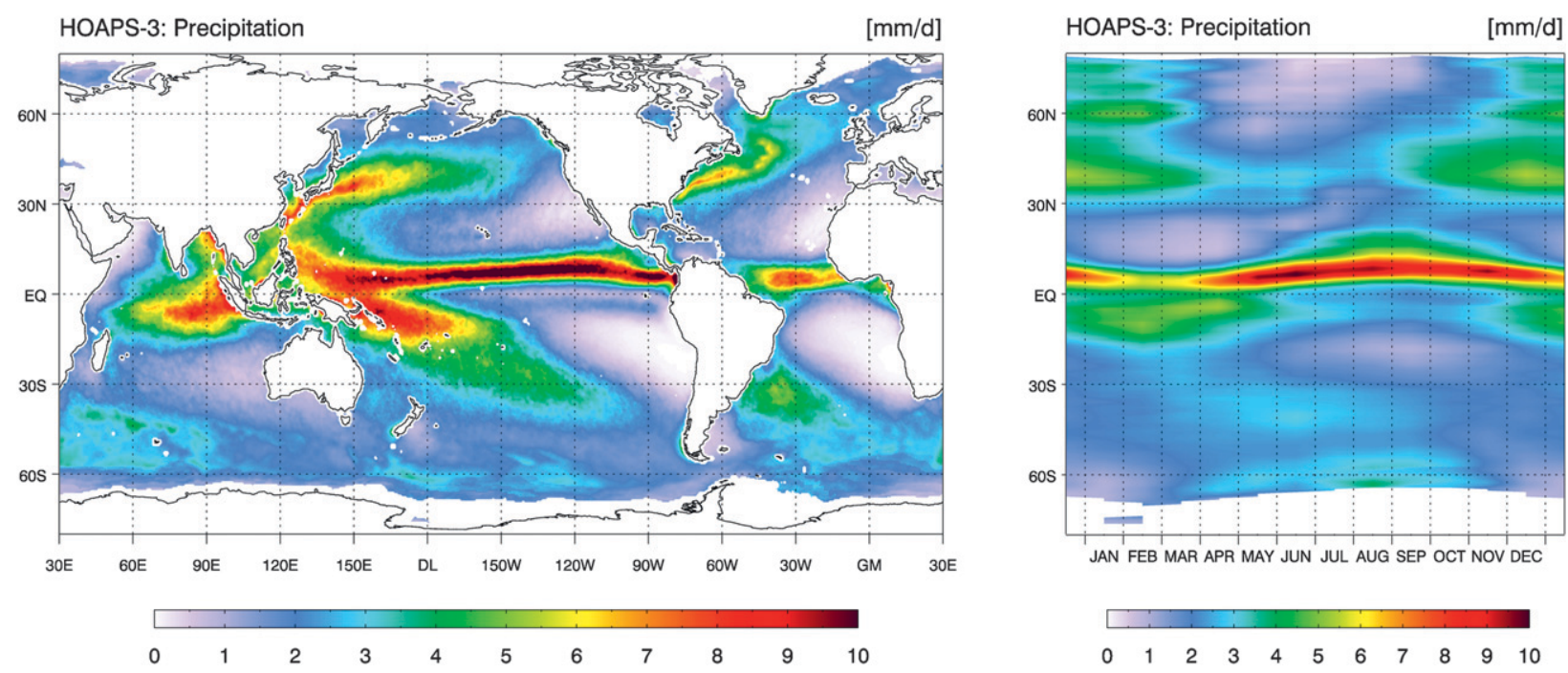

FIG. 7. As in Fig. 1, but for precipitation.

(up to $50 \%$ ). The issue of excessive tropical precipitation is already known from the former ERA-40 reanalysis. However, the tropical moisture budget in ERA-Int appears to be improved over ERA-40, for which this positive bias was even stronger (Simmons et al. 2007). Except for the large tropical biases, the deviations between HOAPS and ERA-Int are small and remain mostly below $1 \mathrm{~mm}$ day $^{-1}(<20 \%)$. HOAPS precipitation values are noticeably larger relative to ERA-Int over the Gulf Stream and Kuroshio currents as well as over the ITCZ region of the central Pacific and the southeastern tip of the SPCZ.

The difference map between HOAPS and TRMM 3B43 precipitation (Fig. 8, upper right) shows in many regions a good agreement between both datasets with deviations below $0.5 \mathrm{~mm}$ day $^{-1}(5 \%-10 \%)$ for most regions. Regionally larger differences are found in regions of high variability over the western Pacific, the SPCZ, and the Indian Ocean. In these regions HOAPS precipitation exceeds the TRMM product by up to $1 \mathrm{~mm} \mathrm{day}^{-1}$. However, because of the high mean values of precipitation the relative deviation remains below $20 \%$. The largest absolute difference is found in the central Pacific ITCZ where HOAPS exceeds TRMM by more than $2 \mathrm{~mm} \mathrm{day}{ }^{-1}$ (locally up to $50 \%$ ). Over the entire North Atlantic basin, HOAPS precipitation is systematically lower relative to the TRMM data, except for the Gulf Stream region. Other regions with lower precipitation in HOAPS are found in the region south of Australia and the northern Indian Ocean.

The comparison of HOAPS with GPCP V2 (Fig. 8, lower right) exhibits similar differences for the tropical belt as the comparison of HOAPS and TRMM. In the subtropical regions HOAPS precipitation is slightly larger than GPCP by values around $0.5 \mathrm{~mm} \mathrm{day}^{-1}(10 \%)$. The maximum deviation of about $1.5 \mathrm{~mm}^{-1 a y}{ }^{-1}(30 \%-$ $40 \%$ ) is found in the Pacific ITCZ. Over the mid-high latitudes between $40^{\circ}$ and $70^{\circ}$ the precipitation in GPCP is systematically $10 \%-30 \%$ higher relative to HOAPS. Locally the values exceed $50 \%$.

\section{3) GLOBAL MEAN TIME SERIES AND ZONAL MEANS}

The global mean time series (Fig. 8, lower left) of the satellite-derived products exhibit values around $3 \mathrm{~mm}$ day ${ }^{-1}$, while the ERA-Int record is constantly higher with $3.4 \mathrm{~mm}$ day $^{-1}$ at the beginning of the time series and $3.2 \mathrm{~mm}$ day $^{-1}$ at the end of the record. The monthto-month variability of the HOAPS record is slightly larger relative to the other datasets. The standard deviation of the monthly global mean values for HOAPS is $0.16 \mathrm{~mm} \mathrm{day}{ }^{-1}$ for the entire record as compared with 0.11 and $0.12 \mathrm{~mm} \mathrm{day}^{-1}$ for GPCP and ERA-Int, respectively. The TRMM product, which is limited to $50^{\circ}$ north and south and starts only in 1998, exhibits a standard deviation of $0.15 \mathrm{~mm} \mathrm{day}^{-1}$. The corresponding value for HOAPS is $0.23 \mathrm{~mm} \mathrm{day}^{-1}$.

For the zonal means (Fig. 8, lower left), the consistency among the satellite-derived products is best between $40^{\circ}$ north and south. The overall bias in this region is low and the tropical and subtropical minima and maxima agree in location and magnitude for these datasets, apart from the northern branch of the ITCZ, which is stronger expressed in HOAPS. For the latter HOAPS agrees with ERA-Int, which, however, exhibits generally higher values relative to the satellite products between 

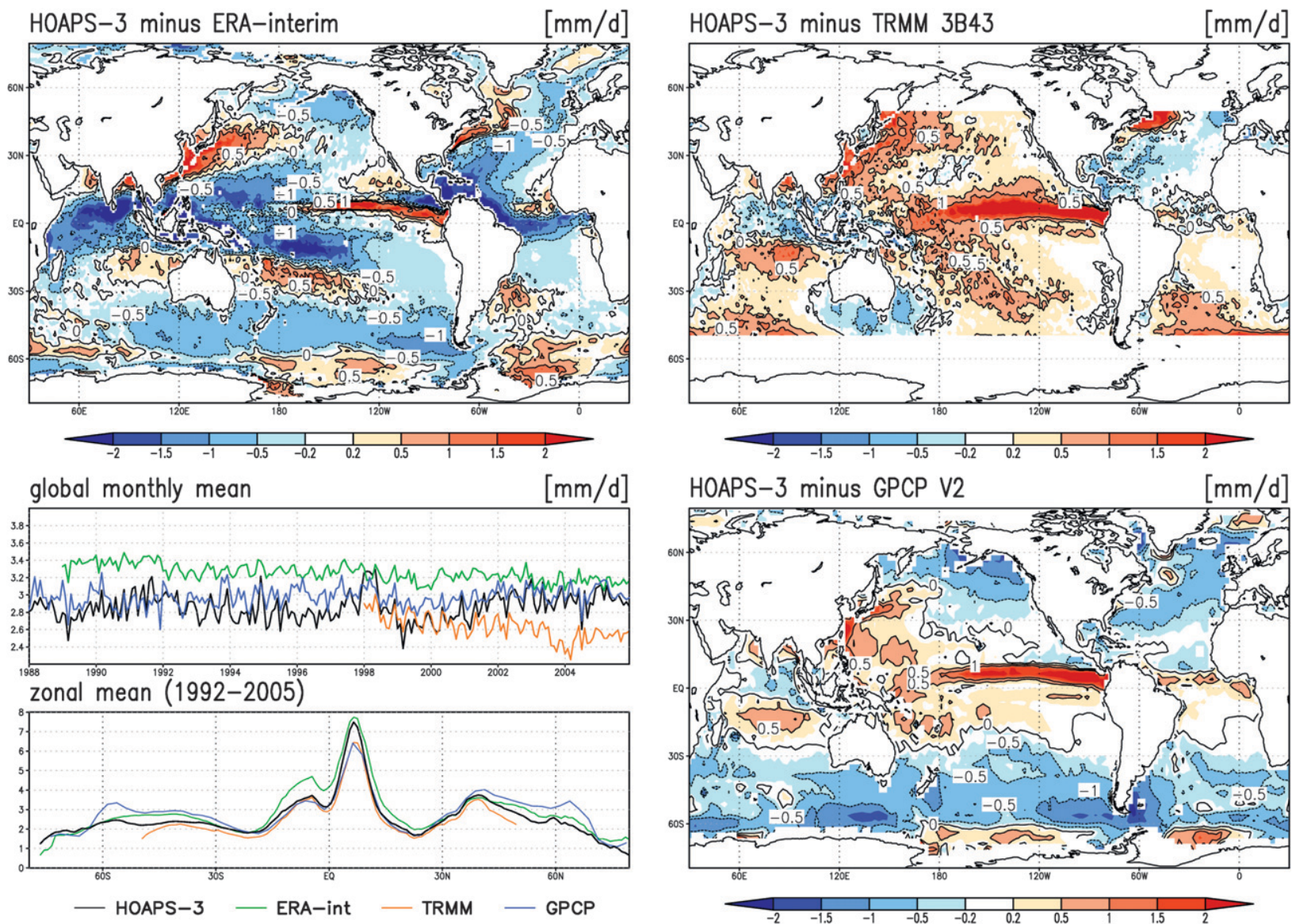

FIG. 8. Difference of the 1992-2005 climate mean HOAPS-3 precipitation and (upper left) ERA-Int, (upper right) TRMM 3B43 (19982005), and (lower right) GPCP V2. (lower left) The global monthly mean precipitation time series of each dataset and the zonal mean precipitation for the overlapping time period 1992-2005 (1998-2005 for TRMM 3B43).

$30^{\circ}$ north and south. In the extratropical regions ERAInt tends to agree better with the satellite products. However, the relative differences between the products increase toward higher latitudes.

\section{e. Freshwater flux}

\section{1) Global Distribution AND ANNUAL CYCLE}

The difference between precipitation and evaporation yields the oceanic freshwater flux into the atmosphere. Dominant features of either precipitation or evaporation fields determine the resulting global distribution of the freshwater flux as shown in Fig. 9. A net flux into the ocean is mainly found in regions of precipitation maxima in the ITCZ, the midlatitude storm tracks, and at high latitudes. In contrast, subtropical regions generate the major part of the freshwater flux into the atmosphere. In the annual cycle, the dominant features of the input parameters are reproduced.

\section{2) COMPARISON OF CLIMATOlOGiCAL MEANS}

The difference map of the climatological mean fields of HOAPS and ERA-Int (Fig. 10, top left) is mostly an inversion of the difference between the precipitation datasets shown in Fig. 8. In the inner tropics the atmospheric freshwater deficit of ERA-Int exceeds HOAPS by up to $2 \mathrm{~mm} \mathrm{day}^{-1}$, while the deficit in HOAPS is larger in the eastern Pacific ITCZ and around $30^{\circ}$ north and south. In the eastern Pacific as well as in the Atlantic the difference in the freshwater flux is mostly determined by the evaporation fields.

The differences between HOAPS and the combination of the IFREMER evaporation and GPCP precipitation are less pronounced in the subtropical regions, except for the warm pool and the ITCZ. In the tropical warm pool region the deviations are dominated by the evaporation pattern, while differences in the ITCZ region are mainly due to the deviations of precipitation. At mid- and high latitudes the positive bias in the GPCP 

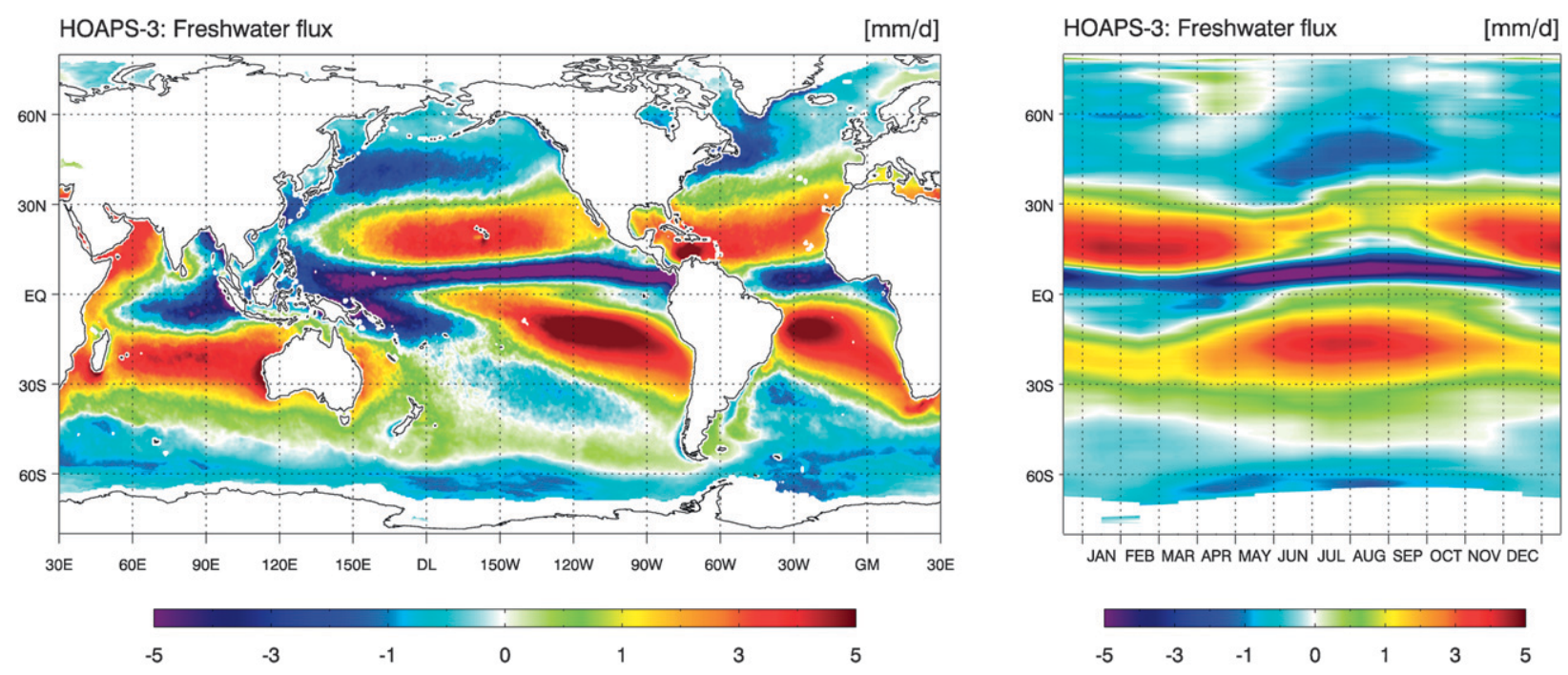

FIG. 9. As in Fig. 1, but for the ocean surface freshwater flux.

precipitation leads to an enhanced freshwater flux into the ocean of IFREMER-GPCP relative to HOAPS.

Additionally, the difference of the combined IFREMER-GPCC product and ERA-Int is depicted in the lower-right panel of Fig. 10. The general patterns of the difference map are similar to the comparison of HOAPS and ERA-Int with regionally larger amplitudes. In particular the positive bias in the subtropics is larger, and the differences in the ITCZ region are inverted.

\section{3) Global MEAN TIME SERIES AND ZONAL MEANS}

The basic structure of the zonal means from each dataset is comparable, as depicted in the lower-left panel of Fig. 10. Nevertheless, especially in the tropical regions distinct differences in the magnitude of the mean freshwater flux are evident. South of the equator the positive values of the satellite-derived products indicate a net freshwater flux into the atmosphere, while ERAInt shows negative values. This enhanced loss of freshwater from the atmosphere into the ocean in ERA-Int leads to global monthly mean values that are generally about $0.2 \mathrm{~mm} \mathrm{day}^{-1}$ lower relative to HOAPS and IFREMER-GPCP. The mean globally averaged HOAPS net ocean surface freshwater flux into the atmosphere for the 1992-2005 period is $0.73 \mathrm{~mm} \mathrm{day}^{-1}$ (IFREMERGPCP: $0.77 \mathrm{~mm}$ day $^{-1}$, ERA-Int: $0.50 \mathrm{~mm}$ day $^{-1}$ ). Furthermore, the time series of both satellite-based datasets exhibit a larger variability with a standard deviation of $0.19 \mathrm{~mm} \mathrm{day}^{-1}$ as compared with $0.10 \mathrm{~mm} \mathrm{day}^{-1}$ for ERA-Int reanalysis data.

\section{Discussion}

\section{a. Wind speed}

The overall low bias of ERA-Int relative to all other datasets (cf. section 3a) is known from previous studies comparing satellite-retrieved and reanalysis wind speeds (Meissner et al. 2001; Kelly et al. 2001; Monahan 2006). The systematic deviations are caused by the different principles used to determine the wind speed. Satellite observations measure the surface wind stress, which is then often recalculated to represent $10-\mathrm{m}$ equivalent neutral-stability wind speed. In contrast to that, reanalysis models simulate the actual winds at $10 \mathrm{~m}$. Another general source for systematic differences is that the reanalyses implement a static sea surface, while satellite measurements are sensitive to ocean surface currents and measure the wind speed relative to the underlying sea surface. Additionally, regionally limited measurements acquired by rawinsondes and the radiative transfer calculations underlying the satellite retrieval algorithms as well as the reanalyses lead to locally different results in the wind speed. The large differences over the monsoon regions of the Bay of Bengal and the Arabian Sea are likely to originate from lack of input data representing the specific atmospheric and sea surface properties in these regions due to atmospheric advection and oceanic upwelling.

The satellite-derived wind speed products, HOAPS and IFREMER, exhibit an overall better agreement with biases below $0.5 \mathrm{~m} \mathrm{~s}^{-1}$ for most regions. Over the Southeast Asian warm pool the IFREMER wind speed shows a high bias relative to the other datasets. In this region the sensitivity of the evaporation to the retrieved 

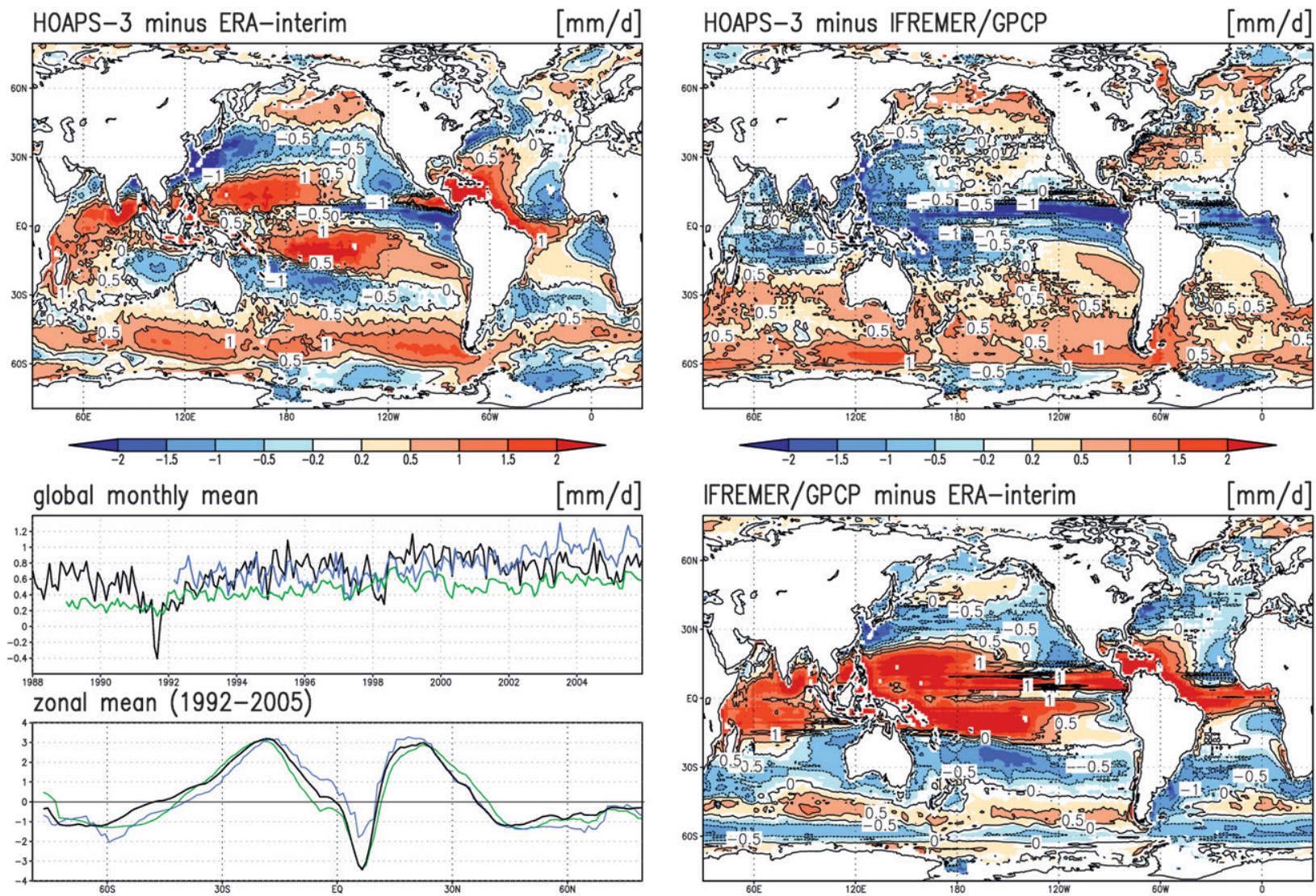

- HOAPS-3 - ERA-int IFREMER/GPCP

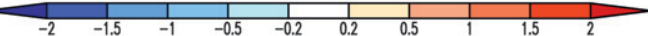

FIG. 10. Difference of the 1992-2005 climate mean HOAPS-3 freshwater flux and (upper left) ERA-Int, (upper right) IFREMERGPCP, and (lower right) IFREMER-GPCP minus ERA-Int. (lower left) The global monthly mean freshwater flux time series of each dataset and the zonal mean freshwater for the overlapping time period 1992-2005.

wind speed is high because of the generally low wind speeds in this region. Therefore, minor differences in wind speed could have a strong impact on the resulting evaporation estimates. The frequently strong precipitation in this region hampers the retrieval of wind speed using microwave radiometers, leading to gaps in the wind speed data. Filling these gaps with scatterometerderived wind speeds as done in the IFREMER dataset may cause biases since scatterometer measurements are also strongly affected by precipitation under certain circumstances. Under low wind speeds and when the scatter from the sea surface is low, additional volume scattering of even light precipitation leads to a spurious wind signal (e.g., Tournadre and Quilfen 2003; Wallcraft et al. 2009). An inverse effect is observed for high wind speed regimes. The NOCS dataset exhibits significant biases at high latitudes. The limited number of observations from these regions in the NOCS dataset is biased toward low wind speeds since ships tend to avoid storms and high sea state related to winds, particularly during the cold season. A similar, but considerably weaker, effect may occur in the HOAPS data because of strong precipitation, which inhibits the retrieval of wind speed from the satellite (Wentz 1997; Andersson et al. 2010b). However, this affects usually only the inner cores of precipitating weather systems and hence only a limited number of satellite observations. In regions with frequent precipitation, such as the ITCZ or the Southern Ocean, this is the case for $10 \%-15 \%$ of the observations.

Estimates of the accuracy of the HOAPS wind speed were carried out by Winterfeldt et al. (2010) who compared HOAPS, Quick Scatterometer (QuikSCAT) SeaWinds scatterometer, and NCEP reanalysis wind speeds with buoy data over the North Sea and North Atlantic. The HOAPS wind retrieval showed RMS values of $2 \mathrm{~m} \mathrm{~s}^{-1}$, which is comparable to the requirement for the scatterometer of the QuikSCAT mission and is regarded to be consistent with values from other studies. It is shown that the HOAPS wind retrieval performs equally well in near-coastal and remote ocean regions. 


\section{b. Near-surface atmospheric specific humidity}

The comparison of $\mathrm{q}_{a}$ from IFREMER and HOAPS exhibits only minor differences because of application of the same algorithm for SSM/I data. Hence, the deviations originate either from different sensor calibrations in the individual SSM/I brightness temperature records or from a different sampling due to the kriging technique used in the IFREMER dataset.

Larger deviations are found in the comparison with NOCS and ERA-Int. In particular, over the subtropical regions, a strong negative bias in the IFREMER and HOAPS satellite retrieval relative to NOCS is evident, which is most expressed during the winter season of each hemisphere. Jackson et al. (2009) found similar patterns in the comparison of different $q_{a}$ satellite retrievals with ICOADS ship and buoy data and related this dry bias to an underestimation of $q_{a}$ by the Bentamy et al. (2003) algorithm in the range of $15-20 \mathrm{~g} \mathrm{~kg}^{-1}$. In comparison of HOAPS with ERA-Int this bias is less pronounced, since ERA-Int is generally dryer in the tropical regions relative to NOCS.

Over the southern oceans, the poor sampling of the ship observations lead to larger uncertainties in the NOCS dataset. Especially during cold seasons, ground observations are sparse, leading to large deviations between the datasets. Over the North Atlantic and Pacific, where the sampling is much better, this problem is not evident. However, the accuracy of satellite retrievals also depends on the representativeness of spatiotemporal variability of their a priori data used during the development of the algorithm. Moreover, the retrieval of $q_{a}$ is not possible for weather situations with strong precipitation.

\section{c. Sea-air humidity difference}

The input parameter for the evaporation retrieval that is related to $q_{a}$ is the sea-air humidity difference. The retrieved evaporation is strongly sensitive to changes in either $q_{s}$ or $q_{a}$. Since $q_{s}$ is directly computed from the SST, the differences of the $q_{s}$ fields of the individual datasets depend on the specific properties of the used SST products. Currently, most datasets use an SST that is derived from AVHRR measurements, which are to date the only long-term satellite-based SST time series with global coverage. This results in generally similar time series for the derived $q_{s}$ that exhibit on climatological scale smaller deviations than the differences found for the $q_{a}$ parameter. Therefore, the comparison patterns for the sea-air humidity difference are mostly similar to the inverted patterns of $q_{a}$ shown in Fig. 4. In the eastern tropical Atlantic the sea-air humidity difference is low biased in HOAPS because of a cold bias in the SST. This is caused by deficiencies in the Pathfinder dataset concerning the correction of errors in the SST retrieval due to high aerosol loadings that originate from the arid zones of the African continent (cf. NODC 2008). This effect is enhanced along the tropical African west coast by a high bias in the HOAPS $q_{a}$ fields in the equatorial regions of the eastern Atlantic. A similar pattern is found in the tropical eastern Pacific.

\section{d. Evaporation}

In the comparison with three other datasets HOAPS shows a slight overall positive bias in regions with high values of evaporation and a somewhat lower negative bias in regions with low evaporation.

When compared with the difference plots of wind speed and $q_{a}$, it appears that the large-scale deviations in evaporation in the tropical regions are primarily caused by differences of the $\mathrm{q}_{a}$ retrievals. The differences in the wind speed and $q_{s}$ are mostly of second-order importance. Exceptions are the strong positive bias of the IFREMER dataset over the tropical warm pool. At higher latitudes, where the sea-air humidity difference is smaller, the influence of the wind speed increases.

The regional deviations in the comparison of HOAPS with ERA-Int and NOCS are larger as compared with the IFREMER product, which turns out to be most consistent with HOAPS. The global mean evaporation for all compared products differs by less than $10 \%$ for most of the investigated time period from 1992 to 2005. This is in accordance with results for global mean estimates of Trenberth et al. (2009) who found similar differences between satellite- and model-based datasets.

Several comparison studies for global ocean evaporation and latent heat flux datasets have been carried out, such as Bourras (2006) and Liu and Curry (2006). These include HOAPS version 2 fluxes, which do not substantially differ from the actual HOAPS-3 values as the flux parameterization scheme did not change since this version and the used Pathfinder SST dataset versions are comparable. In these comparisons HOAPS fluxes already showed good performance. Especially, Bourras (2006) concluded from the comparison of five satellite-derived latent heat flux products that HOAPS is the most appropriate product to study turbulent fluxes over the world oceans.

The reasons of uncertainties in the evaporation estimates point at the retrieval of the relevant parameters wind speed, $q_{a}$, and SST that are affected by precipitation and clouds. Depending on the methodology and sampling density this may lead to errors in the absolute values and the temporal variability in regions with persistent cloud cover and frequent precipitation. Wind speed and $q_{a}$ cannot reliably be retrieved under strong 
precipitation. Similar to the SST, missing values may be interpolated as it is done in the IFREMER product by a kriging procedure. In HOAPS the missing values for $q_{a}$ and wind speed are not interpolated resulting in a considerably lower number of evaporation observations in regions with frequent precipitation. The strongest effect is observed over the Southern Ocean, the ITCZ, and tropical warm pool, where in $10 \%-15 \%$ of all SSM/I observations the retrieval of wind speed, $q_{a}$, and hence evaporation is not possible.

The systematic omission of potentially extreme deviations from the mean values or from the surrounding area may result in unintended biases. A back-of-theenvelope maximum error estimate indicates already that even under the extreme assumption (100\% error of evaporation estimate) would not result in more than about $10 \%$ error for the monthly mean in the most affected regions.

\section{e. Precipitation}

The comparison of HOAPS precipitation with the ERA-Int reanalysis and the two satellite-retrieved climatological products, GPCP V2 and TRMM 3B43, exhibits considerable absolute differences in regions with high precipitation variability. The largest absolute differences are found over the ITCZ, while the relative differences are largest at high latitudes. This is in agreement with previous intercomparison studies that included satellite-based as well as model-based precipitation estimates. These showed regionally large differences among the individual products that are up to $50 \%$ in regions of strong precipitation and at high latitudes (e.g., Adler et al. 2001; Klepp et al. 2005; Beranger et al. 2006). Particularly in the tropical regions model-based data (e.g., reanalysis products) are found to perform significantly poorer than satellite-derived fields (Trenberth and Guillemot 1998; Janowiak et al. 1998; Shinoda et al. 1999).

HOAPS precipitation turns out to be substantially higher relative to the other datasets in the Pacific ITCZ, while the precipitation in subtropical regions agrees well. At higher latitudes between $40^{\circ}$ and $70^{\circ}$ north and south, GPCP V2 exhibits a known high bias relative to HOAPS poleward, while being significantly lower in polar regions (Klepp et al. 2010). In the latitudinal bands from $40^{\circ}$ to $70^{\circ}$ GPCP utilizes Television and Infrared Observation Satellite (TIROS) Operational Vertical Sounder (TOVS) infrared data to compensate deficiencies in the GPCP high-latitude microwave-based retrievals (Adler et al. 2003). At midlatitudes the TOVS data are adjusted to the SSM/I estimates. Toward the poles the adjustment is transitioned to a bias adjustment based on rain gauges. At high latitudes from $70^{\circ}$ and beyond the adjustment is done using land-based rain gauge data.
Comparisons with TRMM products should give deeper insight in the quality of HOAPS precipitation values because of the calibration of the TRMM product with the precipitation radar. In general, the HOAPS precipitation is slightly higher than the TRMM product. This may be in part attributed to a conspicuous decrease in the TRMM 3B43 time series since 2003. This decrease is likely to be caused by the introduction of the Advanced Microwave Sounding Unit-B (AMSU-B) data to the TRMM dataset in 2001-03, which gradually introduced a low bias of about $10 \%$ (GSFC 2007). The effect can also be identified in the global mean time series in the lower-left panel of Fig. 8. When the time series is limited to 1998-2003, the deviations in the subtropical regions are reduced to values around $0.2 \mathrm{~mm}_{\text {day }}{ }^{-1}$.

Because of the lack of reliable in situ measurements, detailed quantitative comparisons for oceanic precipitation are rare and validation efforts are still mostly limited to short period regional intercomparison studies. Moreover, the strong spatial and temporal variability of the precipitation complicates such validation efforts.

In particular the availability of reliable ground data for validation studies is very limited. The only frequent measurements in the central Pacific are taken by several rain gauges on buoys of the Tropical Atmosphere-Ocean (TAO) project and precipitation radars on atolls. The representativeness of measurements from these systems is limited by their spatial restriction and the need of wind corrections for gauge undercatchment. But as these are the only available precipitation dataset, several studies evaluated satellite-based precipitation products using the atoll and buoy data. The results indicate a possible systematic underestimation of inner tropical precipitation up to $15 \%$ by various satellite retrievals (Adler et al. 2001, 2003; Bowman et al. 2009; Sapiano and Arkin 2009). In contrast to that, the new HOAPS retrieval exhibits mostly higher mean precipitation values in this region.

For the mid-high latitudes detailed case study analyses on midlatitude cyclones with intense postfrontal mesoscale convective mixed-phase precipitation were carried out by Klepp et al. (2003). Utilizing in situ voluntary observing ship data, it was shown that, in contrast to other satellite products, HOAPS recognizes smallscale intensive precipitation systems in cold air outbreaks with reliable patterns and intensities. This type of precipitation is also mostly missing in a large sample of events investigated in the ECMWF numerical weather prediction and ERA-40 reanalysis datasets (Klepp et al. 2005). Furthermore, Klepp et al. (2010) demonstrate the ability of HOAPS to detect even light amounts of cold season snowfall with a high accuracy of $96 \%$ between point-to-area collocations of ship-based optical disdrometers and satellite data. 
Also for the North Atlantic region, Andersson et al. (2010a) carried out an analysis of the HOAPS precipitation variability connected to the North Atlantic Oscillation. It is shown that the response of precipitation structures to the atmospheric fluctuations is well represented in HOAPS and that the HOAPS precipitation fields showed convincing consistency with land-based rain gauge data in magnitude and variability.

\section{f. Freshwater flux}

Wentz et al. (2007) demonstrated that satellite data are in principle capable of estimating the global ocean freshwater cycle and that they may be used to evaluate coupled ocean-atmosphere models with respect to the response on global warming. Schlosser and Houser (2007) assessed current satellite-based global water cycle estimates and pointed out advances and deficiencies in the development of such products, such as inconsistencies in global trends as well as a general imbalance between precipitation and evaporation for various datasets. The latter also accounted for the previous version, HOAPS II, which was included in the study of Schlosser and Houser (2007). The former HOAPS II exhibited generally too low global precipitation relative to the evaporation, which lead to an unrealistically large mean freshwater loss of the ocean into the atmosphere. Notwithstanding the uncertainties in the long-term evolution of the global mean freshwater flux, a major improvement of the precipitation parameter was achieved with HOAPS using a new neural network algorithm.

The mean oceanic freshwater flux in HOAPS for the 1992-2005 period is $0.73 \mathrm{~mm} \mathrm{day}^{-1}$, which is equivalent to a liquid water volume of about $90000 \mathrm{~km}^{3} \mathrm{yr}^{-1}$. For a closure of the global freshwater balance, this transport of freshwater from the ocean into the atmosphere should be compensated for the most part by continental runoff. Long-term mean runoff data published and summarized by the Global Runoff Data Center (GRDC) add up to a mean value of approximately $0.32 \mathrm{~mm}$ day $^{-1}$ (equivalent to $40000 \mathrm{~km}^{3} \mathrm{yr}^{-1}$ ) (GRDC 2009). The uncertainties of different runoff estimates are still in the order of $10 \%-20 \%$. Additionally, other runoff sources, such as annual ice melt and groundwater flow into the ocean are estimated to be less than $10 \%$ of the river discharge (Burnett et al. 2001). Comparing these values with the HOAPS global ocean freshwater flux leaves an imbalance of about $0.4 \mathrm{~mm}^{\text {day }}{ }^{-1}$ in the global freshwater balance. For the combined IFREMER/GPCP fields the imbalance is even larger with nearly $0.5 \mathrm{~mm}^{\text {day }}{ }^{-1}$. Also for ERA-Int an imbalance of about $0.2 \mathrm{~mm}$ day $^{-1}$ remains.

While the remaining imbalance appears large at the first glance, it has to be considered that this value is within the limits of variations between the global averages of the individual precipitation and evaporation estimates of about $10 \%-15 \%$. However, this value is beyond the statistical uncertainty of the estimates, with a standard deviation of $0.20 \mathrm{~mm}$ day $^{-1}$ of the HOAPS global mean freshwater flux time series.

\section{Conclusions}

The HOAPS- 3 ocean surface freshwater flux parameters have been compared with evaporation products from ERA-Interim, NOCS v2.0, and IFREMER as well as precipitation fields from ERA-Int, GPCP, and TRMM. The results show that the different estimates of evaporation and freshwater flux strongly depend on the individual input parameters.

While the general patterns are reproduced by all datasets and global mean time series often agree within a range of $10 \%$ of the individual products, locally significant larger deviations occur for all parameters. The satellite-derived datasets often agree better with HOAPS than with ERA-Int or NOCS. However, the compared satellite datasets are not fully independent, as the satellite input data may be of the same origin and/or similar algorithms or parameterizations are used in retrieval procedures. This also accounts to some extent for ERA-Int, which assimilates a wide range of satellite data.

For the evaporation fields, IFREMER and HOAPS agree well at mid- and high latitudes and most of the tropical regions. Larger differences between both datasets are found over the tropical warm pool region. Here the additional use of scatterometer wind speed data is a disadvantage in the IFREMER dataset, since it is strongly affected by precipitation and introduces errors in the IFREMER retrieval. This effect is substantially weaker in the HOAPS wind fields, which are derived using only SSM/I data. Here the resulting evaporation fields agree better with ERA-Int and NOCS. However, in the subtropical regions, the comparisons to ERA-Int and in particular to the ship-based NOCS data indicate a systematic underestimation of $q_{a}$ by the satellite retrieval used in both HOAPS and IFREMER. The strongest effect of this dry bias in $q_{a}$ is found over the central Pacific, where the difference between HOAPS and NOCS average evaporation values exceeds $1.5 \mathrm{~mm}$ day $^{-1}$ or $20 \%$ in some regions. In the eastern tropical Pacific and Atlantic an inverse effect is evident because of a high bias in the HOAPS $q_{a}$ fields. In the comparison of HOAPS and ERA-Int evaporation fields the regional biases appear generally lower, but similar patterns as in the comparison with NOCS appear. At mid- and high latitudes the results for the NOCS dataset regionally depend on the data density of the available ship observations. 
In particular at high latitudes of the Southern Hemisphere the NOCS data exhibit systematic differences when compared with the other datasets. In regions with good data sampling the biases between HOAPS and NOCS are significantly lower.

The most potential for improvement of the evaporation parameter appears to be in the humidity $\left(q_{a}\right)$ retrievals. The comparisons show an improvement in the biases between the individual $q_{a}$ estimates with respect to previous studies by Chou et al. (2004) and Brunke et al. (2002). But particularly in the tropical regions the resulting evaporation difference patterns are still strongly determined by the deviations in the $q_{a}$ fields. More detailed validation efforts are needed to specify the biases against independent in situ data. Recent results using satellite data of the Advanced Microwave Sounding Unit-A (AMSU-A) indicate that the inclusion of the SST as an additional predictor could improve the $q_{a}$ retrieval (Jackson et al. 2009). Further detailed regional analysis of all parameters required to derive the evaporation product is envisaged within the "SEAFLUX" Project of the World Climate Research Programme (WCRP) Global Energy and Water Experiment (GEWEX) Radiation Panel.

In regions with high aerosol load or persistent cloudiness, deficiencies in the SST datasets can cause biases in the $q_{s}$ fields, affecting the sea-air humidity difference of all products. For example, a low bias in the Pathfinder AVHRR SST of the eastern and central tropical Atlantic due to desert aerosols causes an underestimation of $q_{s}$ and thus of the evaporation in HOAPS. Along the African west coast this effects coincides with an overestimation of $q_{a}$ in HOAPS, which enhances the low bias in evaporation. Another unresolved issue is the eruption of Mount Pinatubo in June 1991, which caused large uncertainties in the SST retrievals and hence the flux estimates in the following months.

The precipitation fields of all compared datasets exhibit large differences in highly variable regimes. While the ERA-Int reanalysis appears to be generally high biased in the tropics, a judgment on the differences between the satellite-based retrievals is difficult because of the lack of extensive and reliable in situ precipitation data. Except for the ITCZ regions, the relative differences in the precipitation bands of the tropical regions are mostly below $20 \%$, while the differences for the extratropical regions are found to be much larger, exceeding $50 \%$ regionally. HOAPS is known to perform better than other comparable satellite retrievals at midand high latitudes (Klepp et al. 2010), where the mixed SSM/I and TOVS retrieval from GPCP exhibits a systematic high bias. Global and regional aspects of precipitation validation are carried out and are planned within the framework of the International Precipitation Working Group (IPWG) and the Program to Evaluate High Resolution Precipitation Products (PEHRPP; http://essic.umd.edu/ msapiano/PEHRPP/). Encouraging results on quantitative validation efforts of HOAPS regarding frozen precipitation over the cold-season Nordic seas motivated further ship campaigns in the near future. Additional in situ validation measurements are foreseen for transects of the tropical ITCZ and the Southern Ocean.

The resulting freshwater flux estimates exhibit distinct differences in terms of global averages as well as regional biases. In the tropical regions, the differences in the precipitation estimates mostly determine the freshwater flux difference patterns. The agreement between the HOAPS and the combined IFREMER-GPCP freshwater flux fields is generally better than the agreement of both of them with ERA-Int. However, in comparison with long-term mean global river runoff data of about $0.32 \mathrm{~mm} \mathrm{day}^{-1}$, and even considering their relatively large uncertainties, the ocean surface freshwater balance is not closed by any of the products compared in this study. Since the freshwater flux is the residual of two relatively large values of precipitation and evaporation, a closure of the global balance without constraints from the respective continental values is extremely difficult. With an average value of $0.5 \mathrm{~mm}$ day $^{-1}$ for $E-P$, the remaining imbalance of $0.2 \mathrm{~mm} \mathrm{day}^{-1}$ for ERA-Int is smaller than the satellite-based estimates, but the spatial distribution of the freshwater flux fields appears to be incorrect in the tropical regions because of the excessive precipitation. For HOAPS-3 the global ocean freshwater balance is closed within a range of $10 \%-15 \% \quad\left(0.4 \mathrm{~mm} \mathrm{day}^{-1}\right)$ of the individual global mean evaporation and precipitation estimates. For the combined IFREMER-GPCP fields the imbalance is slightly larger $\left(0.5 \mathrm{~mm} \mathrm{day}^{-1}\right)$.

Based on the comparisons presented in this paper, we conclude that the HOAPS-3 dataset provides consistent fields of evaporation, precipitation, and the resulting freshwater flux that are well suited for further studies of the freshwater flux and related parameters on climatological and regional scale. Overall, the imbalance in the global ocean surface freshwater flux is greatly reduced relative to previous versions of HOAPS because of the new precipitation algorithm in HOAPS-3. Notwithstanding the remaining imbalance, the variability of the freshwater flux parameters with respect to climate indices such as the North Atlantic Oscillation is well represented in HOAPS-3, as shown by Andersson et al. (2010a). However, more detailed validation efforts are needed to explain and, if possible, remove the remaining biases between the different datasets. 
Future tasks will involve the investigation of retrieval uncertainties and hence the specification of error estimates. Moreover, a comprehensive assessment of the long-term stability of satellite-based climatologies is still a not fully resolved issue, which is important for applications regarding local and global trend analyses. As no new SSM/I instruments will be launched into space, a continuation of HOAPS will require the inclusion of new sensors, preferably the Special Sensor Microwave Imager/ Sounder (SSMIS).

HOAPS-3 gridded datasets are freely available as pentad and monthly means and twice daily multisatellite composite fields through the project's Web site (www. hoaps.org). Future releases of HOAPS datasets will be generated at the European Organisation for the Exploitation of Meteorological Satellites (EUMETSAT) Satellite Application Facility on Climate Monitoring (CM-SAF) hosted by the Deutscher Wetterdienst and made available online (http://www.cmsaf.eu/).

Acknowledgments. The enduring funding by the Deutsche Forschungsgemeinschaft (DFG), especially through the Sonderforschungsbereich 512 at the University of Hamburg, as well as the funding by the Helmholtz Foundation through the project Extrop is gratefully acknowledged. The authors thank the ECMWF, IFREMER, NASA, and NOCS for the production and free distribution of their datasets.

\section{REFERENCES}

Adler, R. F., C. Kidd, G. Petty, M. Morissey, and H. Goodman, 2001: Intercomparison of global precipitation products: The third Precipitation Intercomparison Project (PIP-3). Bull. Amer. Meteor. Soc., 82, 1377-1396.

— , and Coauthors, 2003: The Version-2 Global Precipitation Climatology Project (GPCP) monthly precipitation analysis (1979-present). J. Hydrometeor., 4, 1147-1167.

Allan, R. P., and B. G. Liepert, 2010: Anticipated changes in the global atmospheric water cycle. Environ. Res. Lett., 5, 025201 , doi:10.1088/1748-9326/5/2/025201.

Andersson, A., S. Bakan, K. Fennig, H. Graß1, C. Klepp, and J. Schulz, cited 2007: Hamburg Ocean Atmosphere Parameters and Fluxes from Satellite Data-HOAPS-3-Monthly mean. World Data Center for Climate. [Available online at http://cerawww.dkrz.de/WDCC/ui/Compact.jsp?acronym =HOAPS3 MONTHLY.]

— ——, and H. Graß1, 2010a: Satellite derived precipitation and freshwater flux variability and its dependence on the North Atlantic Oscillation. Tellus, 62, 453-468.

—, K. Fennig, C. Klepp, S. Bakan, H. Graß1, and J. Schulz, 2010b: The Hamburg Ocean Atmosphere Parameters and Fluxes from Satellite Data-HOAPS-3. Earth Syst. Sci. Data Discuss., 3, 143-194.

Bentamy, A., K. B. Katsaros, A. M. Mestas-Nunez, W. M. Drennan, E. B. Forde, and H. Roquet, 2003: Satellite estimates of wind speed and latent heat flux over the global oceans. J. Climate, 16, 637-656.
— L. H. Ayina, W. Drennan, K. Katsaros, A. M. Mestas-Nuñez, and R. T. Pinker, 2008: 15 years of ocean surface momentum and heat fluxes from remotely sensed observations. FLUXNEWS, Vol. 5, WCRP Working Group on Surface Fluxes, World Climate Research Programme, Geneva, Switzerland, 14-16. [Available online at http://sail.msk.ru/newsletter/fluxnews_5_final.pdf.]

Beranger, K., B. Barnier, S. Gulev, and M. Crepon, 2006: Comparing 20 years of precipitation estimates from different sources over the world ocean. Ocean Dyn., 56, 104-138.

Berry, D. I., and E. C. Kent, 2009: A new air-sea interaction gridded dataset from ICOADS with uncertainty estimates. Bull. Amer. Meteor. Soc., 90, 645-656.

Bourras, D., 2006: Comparison of five satellite-derived latent heat flux products to moored buoy data. J. Climate, 19, 6291-6313.

Bowman, K. P., C. R. Homeyer, and D. G. Stone, 2009: A comparison of oceanic precipitation estimates in the tropics and subtropics. J. Appl. Meteor. Climatol., 48, 1335-1344.

Brunke, M. A., X. Zeng, and S. Anderson, 2002: Uncertainties in sea surface turbulent flux algorithms and data sets. J. Geophys. Res., 107, 3141, doi:10.1029/2001JC000992.

Burnett, W. C., M. Taniguchi, and J. Oberdorfer, 2001: Measurement and significance of the direct discharge of groundwater into the coastal zone. J. Sea Res., 46, 109-116.

Casey, K. S., 2004: 4-km Pathfinder version 5 user guide. NOAA Tech. Rep., 11 pp. [Available online at http://www.nodc.noaa. gov/SatelliteData/pathfinder4km/PFV50_UserGuide.pdf.]

Chou, S. H., E. Nelkin, J. Ardizzone, R. M. Atlas, and C. L. Shie, 2003: Surface turbulent heat and momentum fluxes over global oceans based on the Goddard satellite retrievals, version 2 (GSSTF2). J. Climate, 16, 3256-3273.

,,,--- and -2004 : A comparison of latent heat fluxes over global oceans for four flux products. J. Climate, 17, 39733989.

Fairall, C. W., E. F. Bradley, D. P. Rogers, J. B. Edson, and G. S. Young, 1996: Bulk parameterization of air-sea fluxes for Tropical Ocean-Global Atmosphere Coupled Ocean-Atmosphere Response Experiment. J. Geophys. Res., 101, 3747-3764.

,,- J. E. Hare, A. A. Grachev, and J. B. Edson, 2003: Bulk parameterization of air-sea fluxes: Updates and verification for the COARE algorithm. J. Climate, 16, 571-591.

GRDC, cited 2009: Surface freshwater fluxes into the world oceans/ Global Runoff Data Centre: Comparisons of GRDC freshwater flux estimate with literature. Federal Institute of Hydrology (BfG), Koblenz, Germany. [Available online at http://www. bafg.de/cln_007/nn_317460/sid_F743821E9F88AD083AD1C494 E3D95FDE/nsc_true/GRDC/EN/02_Services/02__DataProducts/ FreshwaterFluxes/freshflux_node.html?_nnn=true.]

GSFC, cited 2007: Algorithm 3B43-TRMM and other data precipitation. Goddard Space Flight Center. [Available online at http://trmm.gsfc.nasa.gov/3b43.html.]

Hilburn, K. A., and F. J. Wentz, 2008: Intercalibrated passive microwave rain products from the Unified Microwave Ocean Retrieval Algorithm (UMORA). J. Appl. Meteor. Climatol., 47, 778-794.

Hsu, K., X. Gao, S. Sorooshian, and H. Gupta, 1997: Precipitation estimation from remotely sensed information using artificial neural networks. J. Appl. Meteor., 36, 1176-1190.

Huffman, G. J., and Coauthors, 1997: The Global Precipitation Climatology Project (GPCP) combined precipitation dataset. Bull. Amer. Meteor. Soc., 78, 5-20.

, and Coauthors, 2007: The TRMM Multisatellite Precipitation Analysis (TMPA): Quasi-global, multiyear, combined-sensor precipitation estimates at fine scales. J. Hydrometeor., 8, 38-55. 
Jackson, D. L., G. A. Wick, and F. R. Robertson, 2009: Improved multisensor approach to satellite-retrieved near-surface specific humidity observations. J. Geophys. Res., 114, D16303, doi:10.1029/2008JD011341.

Janowiak, J. E., A. Gruber, C. R. Kondragunta, R. E. Livezey, and G. J. Huffman, 1998: A comparison of the NCEP-NCAR reanalysis precipitation and the GPCP rain gauge-satellite combined dataset with observational error considerations. J. Climate, 11, 2960-2979.

Kalnay, E., and Coauthors, 1996: The NCEP/NCAR 40-Year Reanalysis Project. Bull. Amer. Meteor. Soc., 77, 437-471.

Kanamitsu, M., W. Ebisuzaki, J. Woollen, S.-K. Yang, J. J. Hnilo, M. Fiorino, and G. L. Potter, 2002: NCEP-DOE AMIP-II Reanalysis (R-2). Bull. Amer. Meteor. Soc., 83, 1631-1643.

Kelly, K. A., S. Dickinson, M. J. McPhaden, and G. C. Johnson, 2001: Ocean currents evident in satellite wind data. Geophys. Res. Lett., 28, 2469-2472.

Klepp, C. P., S. Bakan, and H. Graß1, 2003: Improvements of satellite-derived cyclonic rainfall over the North Atlantic. $J$. Climate, 16, 657-669.

,-- , and — 2005: Missing North Atlantic cyclonic precipitation in ECMWF numerical weather prediction and ERA40 data detected through the satellite climatology HOAPS II. Meteor. Z., 14, 809-821.

- K. Bumke, S. Bakan, and P. Bauer, 2010: Ground validation of oceanic snowfall detection in satellite climatologies during LOFZY. Tellus, 62, 469-480.

Kubota, M., and H. Tomita, 2007: Introduction of J-OFURO latent heat flux version 2. Proc. Joint 2007 EUMETSAT Meteorological Satellite Conf. and 15th Satellite Meteorology and Oceanography Conf., Amsterdam, Netherlands, EUMETSAT and Amer. Meteor. Soc., 5 pp. [Available online at http://www. eumetsat.int/home/Main/AboutEUMETSAT/Publications/ ConferenceandWorkshopProceedings/2007/groups/cps/ documents/document/pdf_conf_p50_s5_11_kubota_v.pdf.]

Kubota, T., and Coauthors, 2007: Global precipitation map using satellite-borne microwave radiometers by the GSMaP project: Production and validation. IEEE Trans. Geosci. Remote Sens., 45, 2259-2275.

Liu, J. P., and J. A. Curry, 2006: Variability of the tropical and subtropical ocean surface latent heat flux during 1989-2000. Geophys. Res. Lett., 33, L05706, doi:10.1029/2005GL024809.

Liu, W., A. Zhang, and J. Bishop, 1994: Evaporation and solar irradiance as regulators of sea surface temperature in annual and interannual changes. J. Geophys. Res., 99 (C6), 12 623-12 638.

Meissner, T., D. Smith, and F. Wentz, 2001: A 10 year intercomparison between collocated Special Sensor Microwave Imager oceanic surface wind speed retrievals and global analyses. J. Geophys. Res., 106, 11 731-11 742.

Monahan, A. H., 2006: The probability distribution of sea surface wind speeds. Part II: Dataset intercomparison and seasonal variability. J. Climate, 19, 521-534.

Murray, F. W., 1967: On the computation of saturation vapor pressure. J. Appl. Meteor., 6, 203-204.

NODC, cited 2008: 4 km Pathfinder Version 5 User Guide. Silver Spring, Maryland, National Oceanographic Data Center. [Available online at http://www.nodc.noaa.gov/sog/pathfinder4km/ userguide.html.]

Onogi, K., and Coauthors, 2007: The JRA-25 Reanalysis. J. Meteor. Soc. Japan, 85, 369-432.

Sapiano, M. R. P., and P. A. Arkin, 2009: An intercomparison and validation of high-resolution satellite precipitation estimates with 3-hourly gauge data. J. Hydrometeor., 10, 149-166.
Schlosser, C. A., and P. R. Houser, 2007: Assessing a satellite-era perspective of the global water cycle. J. Climate, 20, 13161338.

Schulz, J., P. Schlüssel, and H. Graß1, 1993: Water-vapor in the atmospheric boundary layer over oceans from SSM/I measurements. Int. J. Remote Sens., 14, 2773-2789.

Shinoda, T., H. H. Hendon, and J. Glick, 1999: Intraseasonal surface fluxes in the tropical western Pacific and Indian oceans from NCEP reanalyses. Mon. Wea. Rev., 127, 678-693.

Simmons, A., S. Uppala, D. Dee, and S. Kobayashi, 2007: ERAInterim: New ECMWF reanalysis products from 1989 onwards. ECMWF Newsletter, No. 110, ECMWF, Reading, United Kingdom, 25-35.

Smith, S. D., 1980: Wind stress and heat flux over the ocean in gale force winds. J. Phys. Oceanogr., 10, 709-726.

- 1988: Coefficients for sea surface wind stress, heat flux, and wind profiles as a function of wind speed and temperature. J. Geophys. Res., 93 (C12), 15 467-15 472.

Swift, C. T., L. S. Fedor, and R. O. Ramseier, 1985: An algorithm to measure sea ice concentration with microwave radiometers. J. Geophys. Res., 90, 1087-1099.

Tournadre, J., and Y. Quilfen, 2003: Impact of rain cell on scatterometer data: 1 . Theory and modeling. J. Geophys. Res., 108, 3225, doi:10.1029/2002JC001428.

Trenberth, K. E., and C. J. Guillemot, 1998: Evaluation of the atmospheric moisture and hydrological cycle in the NCEP/NCAR reanalyses. Climate Dyn., 14, 213-231.

— L. Smith, T. Qian, A. Dai, and J. Fasullo, 2007: Estimates of the global water budget and its annual cycle using observational and model data. J. Hydrometeor., 8, 758-769.

_ Bull. Amer. Meteor. Soc., 90, 311-323.

Uppala, S. M., and Coauthors, 2005: The ERA-40 Re-Analysis. Quart. J. Roy. Meteor. Soc., 131, 2961-3012.

Wallcraft, A., A. Kara, C. Barron, E. Metzger, R. Pauley, and M. Bourassa, 2009: Comparisons of monthly mean $10 \mathrm{~m}$ wind speeds from satellites and NWP products over the global ocean. J. Geophys. Res., 114, D16109, doi:10.1029/2008JD011696.

Wentz, F. J., 1997: A well-calibrated ocean algorithm for Special Sensor Microwave/Imager. J. Geophys. Res., 102 (C4), 87038718.

_, L. Ricciardulli, K. Hilburn, and C. Mears, 2007: How much more rain will global warming bring? Science, 317, 233-235.

Winterfeldt, J., A. Andersson, C. Klepp, S. Bakan, and R. Weisse, 2010: Comparison of HOAPS, QuikSCAT and buoy wind speed in the eastern North Atlantic and the North Sea. IEEE Trans. Geosci. Remote Sens., 48, 338-348.

Worley, S., S. Woodruff, R. Reynolds, S. Lubker, and N. Lott, 2005: ICOADS release 2.1 data and products. Int. J. Climatol., 25, 823-842.

Xie, P., and P. Arkin, 1997: Global precipitation: A 17-year monthly analysis based on gauge observations, satellite estimates, and numerical model outputs. Bull. Amer. Meteor. Soc., 78, 2539-2558.

Yu, L. S., and R. A. Weller, 2007: Objectively analyzed air-sea heat fluxes for the global ice-free oceans (1981-2005). Bull. Amer. Meteor. Soc., 88, 527-539.

— X. Jin, and R. A. Weller, 2008: Multidecade global flux datasets from the objectively analyzed air-sea fluxes (OAFlux) project: Latent and sensible heat fluxes, ocean evaporation, and related surface meteorological variables. Tech. Rep. OA2008-01, Woods Hole Oceanographic Institution, OAFlux Project, 64 pp. 